\title{
Validation of Satellite-Based Precipitation Products over Sparsely Gauged African River Basins
}

\author{
VERA THIEMIG \\ Water Resources Unit, Institute for Environment and Sustainability, Joint Research Centre, European Commission, Ispra, Italy, \\ and Faculty of Geosciences, Utrecht University, Utrecht, Netherlands \\ RODRIGO ROJAS \\ Climate Risk Management Unit, Institute for Environment and Sustainability, Joint Research Centre, \\ European Commission, Ispra, Italy \\ MAURICIO ZAMBRANO-BIGIARINI \\ Water Resources Unit, Institute for Environment and Sustainability, Joint Research Centre, European Commission, Ispra, Italy
}

\section{VINCENZO LEVIZZANI}

National Research Council of Italy, Institute of Atmospheric Sciences and Climate (CNR-ISAC), Bologna, Italy

AD De Roo

Water Resources Unit, Institute for Environment and Sustainability, Joint Research Centre, European Commission, Ispra, Italy, and Faculty of Geosciences, Utrecht University, Utrecht, Netherlands

(Manuscript received 9 March 2012, in final form 28 June 2012)

\begin{abstract}
Six satellite-based rainfall estimates (SRFE)—namely, Climate Prediction Center (CPC) morphing technique (CMORPH), the Rainfall Estimation Algorithm, version 2 (RFE2.0), Tropical Rainfall Measuring Mission (TRMM) 3B42, Goddard profiling algorithm, version 6 (GPROF 6.0), Precipitation Estimation from Remotely Sensed Information using Artificial Neural Networks (PERSIANN), Global Satellite Mapping of Precipitation moving vector with Kalman filter (GSMap MVK), and one reanalysis product [the interim ECMWF Re-Analysis (ERA-Interim)] —-were validated against 205 rain gauge stations over four African river basins (Zambezi, Volta, Juba-Shabelle, and Baro-Akobo). Validation focused on rainfall characteristics relevant to hydrological applications, such as annual catchment totals, spatial distribution patterns, seasonality, number of rainy days per year, and timing and volume of heavy rainfall events. Validation was done at three spatially aggregated levels: point-topixel, subcatchment, and river basin for the period 2003-06. Performance of satellite-based rainfall estimation (SRFE) was assessed using standard statistical methods and visual inspection. SRFE showed 1) accuracy in reproducing precipitation on a monthly basis during the dry season, 2) an ability to replicate bimodal precipitation patterns, 3) superior performance over the tropical wet and dry zone than over semiarid or mountainous regions, 4) increasing uncertainty in the estimation of higher-end percentiles of daily precipitation, 5) low accuracy in detecting heavy rainfall events over semiarid areas, 6) general underestimation of heavy rainfall events, and 7) overestimation of number of rainy days in the tropics. In respect to SRFE performance, GPROF 6.0 and GSMaP-MKV were the least accurate, and RFE 2.0 and TRMM 3B42 were the most accurate. These results allow discrimination between the available products and the reduction of potential errors caused by selecting a product that is not suitable for particular morphoclimatic conditions. For hydrometeorological applications, results support the use of a performance-based merged product that combines the strength of multiple SRFEs.
\end{abstract}

Corresponding author address: Vera Thiemig, Via E. Fermi 2749, TP 261, 21027 Ispra (VA), Italy.

E-mail: vera.thiemig@jrc.ec.europa.eu 


\section{Introduction}

Precipitation is a key steering factor for many socioeconomic activities in Africa (Dinku et al. 2007). Its variability has an enormous impact throughout the continent, with those countries relying on rain-fed agriculture being particularly prone to adverse economic effects. At the same time, precipitation extremes can lead to flooding and droughts, which may result in the loss of human life by drowning or starvation (Dinku et al. 2007). Reliable precipitation information is therefore of utmost importance to be able to correctly assess water resource availability or potential water-related risks within the African continent.

Large efforts have been made in the development of modeling tools that facilitate, inter alia, water resource management through optimization, planning, prevention, protection, and mitigation measures, which aim to reduce both socioeconomic and human losses. The successful application of these models, however, relies heavily upon the accuracy of one of their main inputs: the precipitation data (Behrangi et al. 2011; Hughes 2006). The ground-based precipitation observation network in Africa is, however, steadily deteriorating mainly because of inadequate funding arising from more pressing economic issues (Hughes 2006). In many cases, ground measurements are not suitable to be used as input data for many applications (e.g., hydrological modeling) because of an insufficient number of ground measurement stations, a large proportion of missing values, unreliability of the records, reporting time delays, and limited accessibility to available data (Dinku et al. 2007; Hughes 2006). An alternative to overcome these shortcomings may lie in the field of remote sensing, which provides SRFE (Grimes and Diop 2003; Hughes 2006) that can potentially be used for hydrological applications. (Note that all acronyms used in this paper are expanded in the glossary in the appendix.)

SRFEs are becoming increasingly available and accessible in near-real time with almost global coverage. Temporal and spatial resolution, as well as measurement accuracy, are continuously improving owing to steady advances in sensor technology and new methods for merging various data sources (e.g., geostationary thermal IR, PMW, radar, and information from the GTS) (Kidd et al. 2009; Stisen and Sandholt 2010). To date, several high-resolution SRFE products are at an operational stage, with a rapidly growing scientific community using these data to supplement or even replace rain gauge observations (Dinku et al. 2007).

The quality of the SRFE data largely determines the performance of any potential hydrological application (Yilmaz et al. 2005). Limitations in the algorithms that form the basis of the SRFE, as well as systematic biases
(Smith et al. 2006), can cause serious discrepancies between SRFE and ground observations. These discrepancies will introduce unwanted uncertainties in the results of hydrological applications that, in the worst case, may lead to the wrong conclusions and hence poor management decisions, which can subsequently result in devastating consequences in the case of flood nowcasting.

Notwithstanding the fact that large efforts have been made to reduce discrepancies between SRFE and ground observations (Tian et al. 2010), SRFE products still require in-depth validation against ground observations to increase the understanding of their quality and to quantify the appropriate level of confidence in their use in different applications (Dinku et al. 2007; Hong et al. 2006). Despite this need for validation, most of the existing SRFE validation work carried out in Africa 1) has focused on a specific region (Asadullah et al. 2008; Dinku et al. 2010b; Diro et al. 2009; Laurent et al. 1998; Stisen and Sandholt 2010), 2) has assessed single or few SRFEs (Hughes 2006; McCollum et al. 2000; Nicholson et al. 2003; Symeonakis et al. 2009; Thorne et al. 2001), or 3) has performed large-scale analyses considering only low spatial $\left(2.5^{\circ}\right)$ and temporal (monthly) resolution products (Adler et al. 2003; Ali et al. 2005; Xie and Arkin 1995). A validation study covering several regions across Africa and employing an ensemble of finer spatiotemporal resolution SRFE is therefore of utmost importance for the current status, which has been explicitly stressed by Symeonakis et al. (2009) and Hughes (2006).

The aim of this work is to present an intercomparable validation study of several SRFEs over different topographic and climatic zones (in the following referred to as "morphoclimatic zones") in Africa and, therefore, the study considers various hydrological regimes. It should be noted that the validation focuses, besides the general ability of the SRFEs to replicate daily and monthly rainfall, on characteristics such as annual catchment totals, spatial distribution patterns, seasonality, number of rainy days per year, and timing and volume of heavy rainfall events. We believe these characteristics form the basis of certain hydrological applications such as drought and flood monitoring, or large-scale water balance estimations, which are of particular interest in Africa. With this work we aim, firstly, to identify the strengths and limitations of SRFE products for different morphoclimatic regions and, secondly, to determine the SRFE product(s) that show the best overall performance for conditions reflecting the current data availability in Africa.

For validation purposes we used six SRFE and one reanalysis product-namely, CMORPH, RFE 2.0, TRMM 3B42 v6, GPROF 6.0, PERSIANN, GSMaPMVK, and ERA-Interim (see Table 2 for details). These products were selected because of their spatial and 


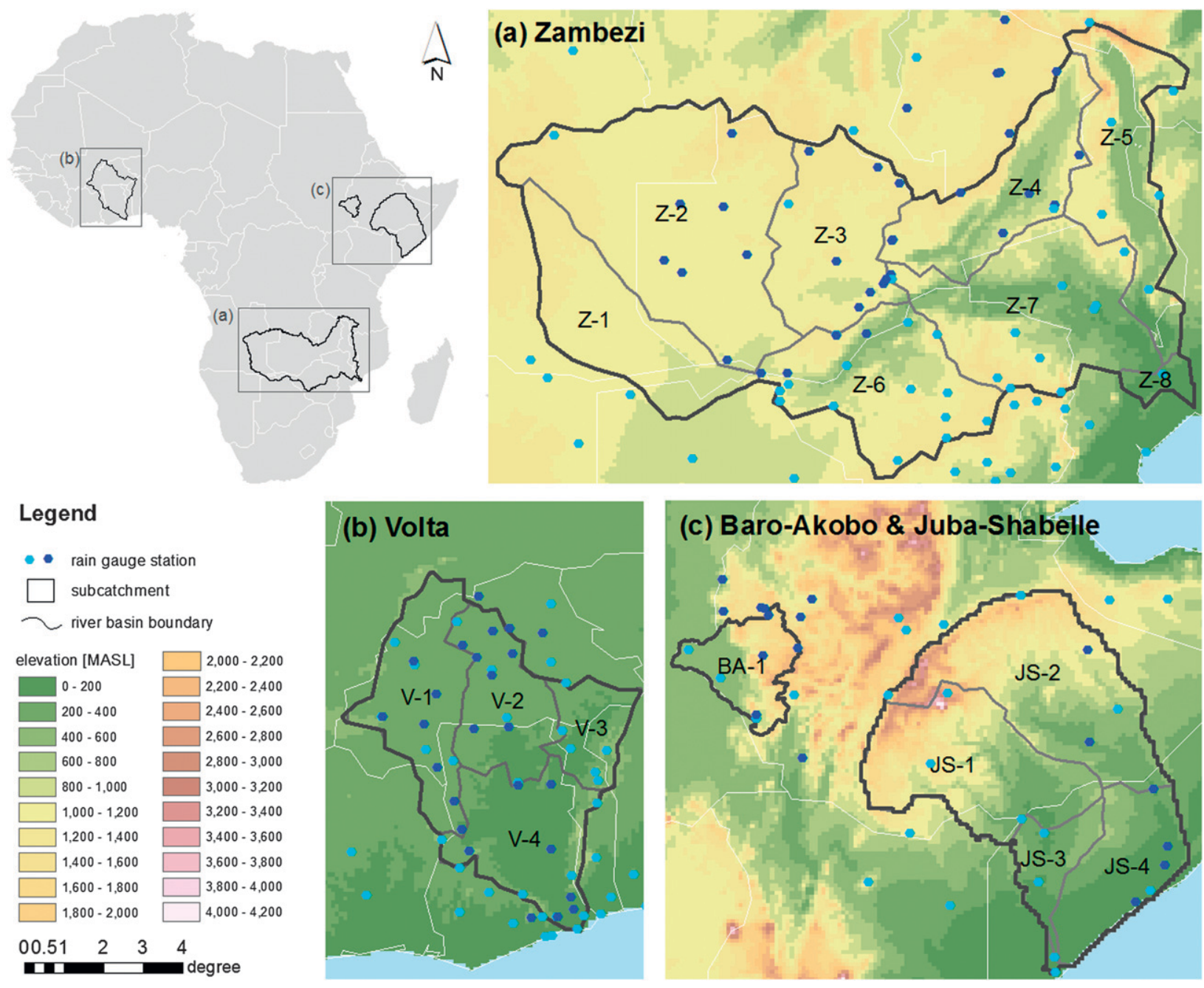

FIG. 1. Overview of the geographical location of the study areas: (a) terrain elevation, (b) rain gauge stations, and (c) subcatchment delineation. Dark blue dots show rain gauge stations used for the point-to-pixel analysis, while (light and dark) blue dots show stations used for the large-scale analysis (spatial interpolation with KED).

temporal resolution, which makes them particularly suitable for hydrological applications. The performance of the SRFEs was assessed over four African river basins-namely, the Zambezi, Volta, Juba-Shabelle, and Baro-Akobo. Considering the temporal and spatial variability of rainfall characteristics and the conventional hydrological working units, the validations were carried out on a point-to-pixel, subcatchment, and river basin scale. To maximize the use of information, ground observations were interpolated using KED (Goovaerts 2000), where high-resolution terrain elevation data were used as the external drift to improve spatial interpolation of precipitation. The performance of the SRFE was assessed using statistical measures of performance (e.g., pBIAS, $r$, and $\mathrm{NS}_{\text {eff }}$ ) and visual comparison methods.

In section 2, we present details on the study area, rain gauge data used for validation, and SRFE. Methodology and results are presented in sections 3 and 4, respectively, and a more comprehensive discussion including conclusions and recommendations can be found in section 5 . Finally, a glossary of commonly used abbreviations is presented in the appendix.

\section{Study area and datasets}

\section{a. Study area}

Four African river basins were selected for validation of the SRFE-namely, the Zambezi, Volta, JubaShabelle, and Baro-Akobo (see Fig. 1).

The Zambezi River basin is located in southern Africa and is one of the largest transboundary river basins in Africa, comprising eight countries (Angola, Botswana, Malawi, Mozambique, Namibia, Tanzania, Zambia, and Zimbabwe) (see Fig. 1a). It has a drainage 
area of approximately $1.35 \times 10^{6} \mathrm{~km}^{2}$, ranging in height from $1524 \mathrm{~m}$ MSL to sea level, with three distinct climatic seasons: cool and dry (April-August), warm and dry (September-October), and warm and wet (NovemberMarch), resulting in an unimodal pluviometric regime. The annual precipitation varies between $700 \mathrm{~mm}$ for the southern and southwestern areas and $1200 \mathrm{~mm}$ for the northern areas, with an average of $990 \mathrm{~mm}$ (Shahin 2002).

The Volta River basin is shared by Benin, Burkina Faso, Ghana, the Ivory Coast, Mali, and Togo (see Fig. 1b), covering an area of circa $394000 \mathrm{~km}^{2}$. Notwithstanding the regular topography, the basin's climate shows a distinct north-south gradient due to the movement of the ITCZ, which creates a steadily increasing precipitation gradient from the dry Sahelian north (300$500 \mathrm{~mm} \mathrm{yr}^{-1}$ ) to the oceanic south (1200-1500 $\mathrm{mm} \mathrm{yr}^{-1}$ ) (Shahin 2002). Along this gradient the pluviometric regime also changes from a short unimodal pattern for the inland areas to a longer, slightly bimodal pattern for the coastal zones.

The Juba-Shabelle Rivers basin covers an area of circa $783000 \mathrm{~km}^{2}$ and is shared by Ethiopia, Somalia, and Kenya (see Fig. 1c). Few distinctive climatic regimes are associated with the basin's highly complex topography. These regimes are mostly determined by the northward and southward movement of the ITCZ resulting in subhumid and semiarid conditions with two distinctive rain seasons (April-June and OctoberNovember). Except for in the limited coastal zones, annual precipitation mostly follows a bimodal pattern. The average annual precipitation of the basin is $500 \mathrm{~mm}$, with considerable spatial variability between the Ethiopian highlands $(1300 \mathrm{~mm})$, the lowlands between Somalia and Ethiopia $(200 \mathrm{~mm})$, and the coastal zone $(500 \mathrm{~mm})$ (Artan et al. 2007).

The smallest basin analyzed corresponds to the BaroAkobo River, which is part of the Nile River basin (see Fig. 1c). This basin is located in southwest Ethiopia

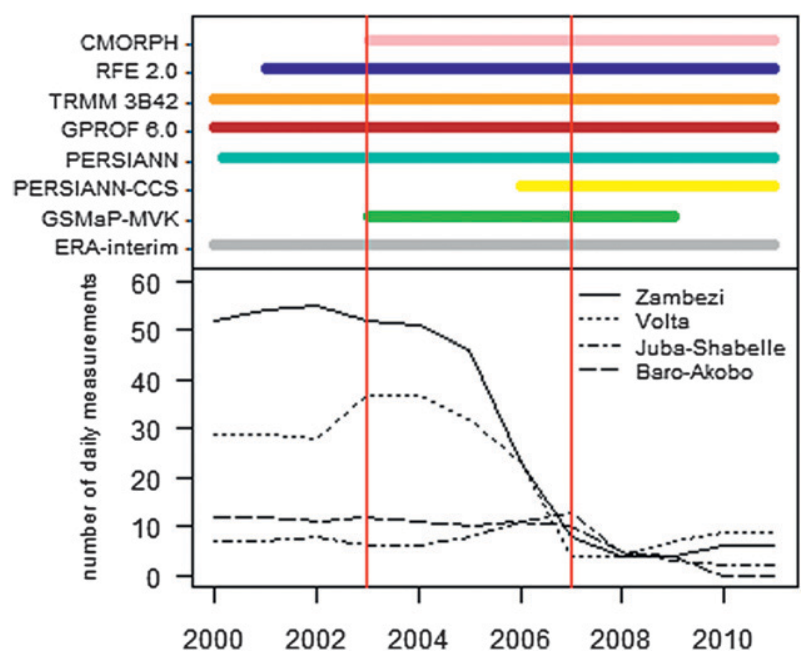

FIG. 2. Temporal coverage of SRFE and ground measurements between 2000 and 2010. Vertical red lines show, the delimitation of the validation period (2003-06) used in this work.

covering an area of circa $76000 \mathrm{~km}^{2}$ with an altitude ranging between 400 and $3100 \mathrm{~m}$ MSL. Annual precipitation varies from 1800 to over $2200 \mathrm{~mm}$, with one rainy season from April to October.

\section{b. Datasets}

\section{1) RAIN GAUGE DATA}

The dataset used for validation comprised 205 gauge stations distributed over the four river basins (see Fig. 1). The varying number of daily ground observations for each river basin between 2000 and 2010 is depicted in Fig. 2. Table 1 provides, for each river basin, details regarding number of rain gauge stations, data source, and data coverage, as well as gauge density.

This dataset is considered to be the most representative for a validation study of this kind. First, this dataset complements the publicly available GTS data frequently used for bias correction of SRFE (e.g., RFE

TABLE 1. Summary of rain gauge data used in this work. GLOWA stands for Global Change in the Hydrological Cycle (http://www.glowavolta.de/), and SWALIM stands for Somalia Water and Land Information Management.

\begin{tabular}{|c|c|c|c|c|c|c|c|}
\hline \multirow[b]{2}{*}{ Target area } & \multirow{2}{*}{$\begin{array}{c}\text { No. of } \\
\text { stations }\end{array}$} & \multirow[b]{2}{*}{ Provider } & \multicolumn{4}{|c|}{$\begin{array}{c}\text { Data coverage between } 2003 \text { and } 2006 \\
\text { (No. of stations) }\end{array}$} & \multirow{2}{*}{$\begin{array}{l}\text { Gauge density } \\
\left(\mathrm{km}^{2} \text { station }^{-1}\right)\end{array}$} \\
\hline & & & $<25 \%$ & $25 \%-50 \%$ & $50 \%-75 \%$ & $>75 \%$ & \\
\hline \multirow[t]{2}{*}{ Zambezi } & 96 & Zambia Meteorological Department & 5 & 3 & 23 & 23 & 22900 \\
\hline & & WMO GTS stations & 43 & 7 & 4 & 0 & \\
\hline \multirow[t]{2}{*}{ Volta } & 68 & GLOWA Volta project & 3 & 1 & 2 & 22 & 8800 \\
\hline & & WMO GTS stations & 20 & 13 & 4 & 3 & \\
\hline \multirow[t]{2}{*}{ Juba-Shabelle } & 26 & $\begin{array}{l}\text { Ethiopian National Meteorological } \\
\text { Department/SWALIM project }\end{array}$ & 5 & 2 & 0 & 4 & 52000 \\
\hline & & WMO GTS stations & 12 & 0 & 2 & 1 & \\
\hline Baro-Akobo & 15 & $\begin{array}{l}\text { Ethiopian National Meteorological } \\
\text { Department }\end{array}$ & 3 & 0 & 1 & 11 & 12700 \\
\hline
\end{tabular}


TABLE 2. Summary of SRFEs used in this work. EORC stands for Earth Observation Research Center (http://www.eorc.jaxa.jp/ en/index.php).

\begin{tabular}{|c|c|c|c|c|c|c|}
\hline Product & Provider & Spatial coverage & $\begin{array}{l}\text { Temporal } \\
\text { coverage }\end{array}$ & $\begin{array}{l}\text { Spatial } \\
\text { resolution }\end{array}$ & $\begin{array}{l}\text { Temporal } \\
\text { resolution }\end{array}$ & References \\
\hline CMORPH & NOAA-CPC & $60^{\circ} \mathrm{N}-60^{\circ} \mathrm{S}$, globally & Since 6 Dec 2002 & $0.25^{\circ}$ & $3 \mathrm{~h}$ & (Joyce et al. 2004) \\
\hline RFE 2.0 & NOAA-CPC & $40^{\circ} \mathrm{N}-40^{\circ} \mathrm{S}, 20^{\circ} \mathrm{W}-55^{\circ} \mathrm{E}$ & Since 1 Jan 2001 & $0.1^{\circ}$ & $24 \mathrm{~h}$ & $\begin{array}{l}\text { (The NOAA Climate } \\
\text { Prediction Center 2002) }\end{array}$ \\
\hline TRMM 3B42 v6 & NASA & $50^{\circ} \mathrm{N}-50^{\circ} \mathrm{S}$, globally & Since 1 Jan 1998 & $0.25^{\circ}$ & $3 \mathrm{~h}$ & (Huffman et al. 2010, 2007) \\
\hline GPROF 6.0 & NASA & globally & Since 1 Jan 1998 & $0.25^{\circ}$ & $24 \mathrm{~h}$ & $\begin{array}{l}\text { (Kummerow et al. 2001; } \\
\text { Olson et al. 2007) }\end{array}$ \\
\hline PERSIANN & $\begin{array}{l}\text { University of } \\
\text { Arizona }\end{array}$ & $60^{\circ} \mathrm{N}-60^{\circ} \mathrm{S}$, globally & Since 1 Mar 2000 & $0.25^{\circ}$ & $6 \mathrm{~h}$ & (Hsu et al. 1997) \\
\hline GSMaP-MVK & JAXA/EORC & $60^{\circ} \mathrm{N}-60^{\circ} \mathrm{S}$, globally & $\begin{array}{l}1 \text { Jan } 2003-31 \\
\text { Dec } 2008\end{array}$ & $0.1^{\circ}$ & $1 \mathrm{~h}$ & (Ushio and Kachi 2010) \\
\hline ERA-Interim & ECMWF & Global & $\begin{array}{l}1 \text { Jan } 1989-31 \\
\text { Dec } 2009\end{array}$ & $\sim 79 \mathrm{~km}$ & $6 \mathrm{~h}$ & (Dee et al. 2011) \\
\hline
\end{tabular}

2.0, TRMM-3B42, and ERA-Interim) with data from national meteorological services that are not publicly available. Approximately $79 \%$ of the data used here are not publicly available and hence are only used rarely in validation studies. Secondly, all data providers claim to perform quality control procedures to reduce potential errors. Therefore, and in spite of the highly varying data coverage and the uneven spatial distribution (i.e., high density at lower elevations and just few stations at higher altitude), we consider this dataset to be representative as it is the most complete and accurate, given the general data availability for each river basin.

\section{2) SRFE}

This section provides a brief overview of the SRFE products (see Table 2 for details) and the main findings of previous validation studies. From Fig. 2 we observe that, for almost all of the SRFE products, there are concurrent data periods between the years 2003 and 2006, which coincide with the maximum number of available daily rainfall records taken from the rain gauge stations in the four river basins. Based on this, we selected the SRFE products described below.

\section{(i) $C M O R P H$}

The main inputs for the NOAA-CPC CMORPH are geostationary IR data from the U.S. GOES-8 and -10 , the European Meteosat-5 and -7, and the Japanese GMS-5, PMW-derived precipitation data from the TMI, the SSM/ I, and the AMSU. CMORPH merges IR and PMW data in two steps: 1) atmospheric motion vectors from two successive IR images are generated at 30-min intervals, and 2) the derived motion field is used to propagate the precipitation estimates derived from the different PMW sources. Hence, quantitatively, the precipitation estimates are based solely on PMW data (Joyce et al. 2004) and the IR imagery is not used to estimate precipitation but rather to interpolate between two PMW-derived rainfall intensity fields. CMORPH has been reported to outperform other SRFE products over the Australian tropics (Ebert et al. 2007; Joyce et al. 2004), central United States (Behrangi et al. 2011), and Europe, whereas it performed similarly to other SRFE products over the Ethiopian highlands (Dinku et al. 2007) and poorly over western tropical Africa (Jobard et al. 2011). In respect of quantitative rainfall estimation, CMORPH tends to overestimate the amount of precipitation during wet periods, which is a common characteristic for SRFE products that do not rely on rainfall gauge data (Behrangi et al. 2011).

(ii) RFE 2.0

The NOAA African Precipitation Estimation Algorithm (RFE 2.0) is based on IR (Meteosat-5) and PMW (SSM/I and AMSU) data as well as on GTS rain gauge station data. Estimates are generated in two steps: 1) satellite data sources are linearly combined through an ML estimation method (Arkin and Meisner 1987) to eliminate data gaps and to decrease random errors and systematic bias, and 2) a bias correction method is implemented on a grid-to-grid basis using the GTS rain gauge stations to correct for quantitative deviations (The NOAA Climate Prediction Center 2002; Xie and Arkin 1996). The performance of RFE 2.0 is strongly dependent on the observational network density with deviations increasing in mountainous and deserted areas (Symeonakis et al. 2009). In addition, orographic rainfall effects are not included in RFE 2.0, resulting in considerable underestimation of precipitation over mountainous regions (Dinku et al. 2007). Over the Sahelian region in western Africa, RFE 2.0 estimates provided a superior match over other SRFE products in terms of spatial pattern and bias (Jobard et al. 2011). 


\section{(iii) TRMM 3B42 v6}

The main input sources for the Tropical Precipitation Measuring Mission TRMM 3B42 v6 are IR data from geostationary satellites, PMW data from TMI, SSM/I, AMSU, and the AMSR-E. The 3B42 algorithm is executed in four steps: 1) PMW precipitation estimates are calibrated and combined;2) IR precipitation estimates are generated using the calibrated PMW data; 3) both IR and PMW data are then combined; and 4) rescaled on a monthly basis using rain gauge data (Huffman et al. 2010). TRMM 3B42 v6 performed well compared with other SRFE products, highlighting a good match for the frequency of the rainy events and a weaker match for the amount of precipitation (Huffman et al. 2010). These findings have been confirmed over Uganda by Asadullah et al. (2008).

\section{(iv) GPROF 6.0}

The GPROF 6.0 precipitation estimates are based on the SSM/I brightness temperature data only. The basis of this algorithm is a large supporting database of observed multichannel microwave radiances and simulated radiance profiles, together with the corresponding precipitation rate generated from a numerical model. The actual precipitation estimate is then retrieved in two steps: 1) the observed microwave radiances are uploaded into the database and a (pseudo)-radiative filtering is performed, and 2) the precipitation rate is then generated by fitting the observed radiance profile with the reference profiles in the database (Kummerow et al. 2001; Olson et al. 2007). Compared with other products, validation studies of GPROF 6.0 were limited, reporting a positive bias $(17 \%-20 \%)$ when compared with the GPCC rain gauge network (Kummerow et al. 2001).

\section{(v) PERSIANN}

The PERSIANN method utilizes an ANN model to estimate precipitation using IR; accuracy is improved by adaptive adjustment of the network parameters using rainfall estimates from the TMI. At the pixel level, the algorithm fits the mean and standard deviation of the brightness temperature of a pixel and the adjacent pixel's temperature texture to the calculated precipitation rate (Hong et al. 2004; Hsu et al. 1997). PERSIANN has been reported to be less consistent with rain gauge data over a number of areas such as Uganda (Asadullah et al. 2008), India (Brown 2006), Colombia (Dinku et al. 2010b), Asia (Sorooshian et al. 2000), and the Ethiopian highlands (Dinku et al. 2007). These studies show large errors for higher precipitation amounts, which can be explained by the lack of rain gauge adjustment, although high correlations with gauge data have been reported for a number of South African river basins (Hughes 2006).

\section{(vi) GSMaP-MVK}

The main data sources for the GSMaP-MVK are PMW (TMI, AMSR-E, AMSR, and SSM/I) and IR (GOES-8 and -10, Meteosat-5 and -7, and GMS) radiometer data. The algorithm follows three main steps: 1 ) retrieval of precipitation rate from PMW data using a Kalman filter approach (Ushio et al. 2009), 2) propagation of the estimated precipitation rate using the same procedure as CMORPH, and 3) refinement of precipitation data based on the relationship between the IR brightness temperature and surface precipitation rates. Previous validation studies showed underestimation of precipitation amounts and a very low probability of precipitation detection over Colombia (Dinku et al. 2010b) and the West African monsoon region (Jobard et al. 2011), whereas its performance was reported to be comparatively better than TRMM 3B42 over arid and semiarid areas in Africa (Dinku et al. 2010a).

\section{(vii) ERA-Interim}

As a reanalysis product, ERA-Interim is a result of available observations but it is not equivalent to observations. Precipitation is estimated by the numerical model based on temperature and humidity information derived from assimilated observations originating from PMW and in situ measurements (Dee et al. 2011). Intercomparison studies between ERA-Interim and the previously mentioned products, as well as validation against ground measurements, are limited. ERA-Interim was outperformed by ERA-40 and RFE 2.0 over Uganda (Maidment et al. 2010).

\section{Methodology}

\section{Validation}

The prerequisite for the choice of validation period was a common time period between all SRFE and rain gauge data. The varying number of ground observations for each river basin and the different starting dates of the individual SRFEs are shown in Fig. 2, which shows that the best available time period is from 2003 to 2006 .

The ability of the SRFEs to replicate specific rainfall characteristics was assessed. The rainfall features validated in this work include volume and timing of heavy rainfall events, number of rainy days per year, annual catchment totals, spatial distribution patterns, seasonality, and average daily and monthly rainfall values. Considering the temporal and spatial variability of these characteristics, 
as well as conventional hydrological working units, the SRFE validation was carried out on three spatially aggregated levels: point-to-pixel, subcatchment, and river basin scale.

\section{1) Point-TO-PIXEL ANALysis}

The volume and timing of heavy rainfall events and the number of rainy days per year are largely subject to small-scale variability and, thus, can only be validated at the smallest possible spatial scale. Hence, a point-topixel analysis was applied in order to compare time series rainfall data observed at selected gauge stations (dark blue points in Fig. 1) with the respective SRFE grid cell. For this analysis, all SRFE products with a larger spatial resolution than $0.1^{\circ}$ were downscaled to a unified grid of $0.1^{\circ}$ resolution, thus eliminating uncertainties arising from incongruent SRFE grid resolutions. For each of the selected meteorological stations, only years with $100 \%$ data coverage were considered for the comparison (called analytical years, $n$ ).

The replication of volume and timing of heavy rainfall events was assessed by considering only the highest observed rainfall event for each analytical year $(n)$, as shown in Fig. 3. For the timing of the event, the lag time between the maximum precipitation value observed and estimated (SRFE) was calculated using a reference period of one week around the highest observed value $\left(t_{0}\right)$, with 3 days before $\left(t_{-3}\right)$ and 3 days after $\left(t_{+3}\right)$ the highest observed value $\left(t_{0}\right)$. If the SRFE do not exceed $10 \mathrm{~mm}$ on any of the days within this reference period, an NP class was assigned, which represents a failure of the SRFE to capture the signal of the highest observed rainfall event within the period $\left(t_{-3}, t_{+3}\right)$. The number of NPs therefore reflect the ability of the different SRFE products to capture the rainfall events. A low number of NPs indicate that the SRFE product is capable of capturing the signal of the observed rainfall event, whereas a high number of NPs indicate that the signals of the events were not captured.

For rainfall volume during the highest events, and given that the maximum SRFE precipitation might be shifted with respect to its observed counterpart, the accumulated precipitation for the whole week $\left(t_{-3}, t_{+3}\right)$ was assessed. To facilitate comparison, rainfall totals of the highest events were normalized using

$$
P_{\text {amount }}=\frac{1}{n} \sum_{i=1}^{n} \frac{P_{\mathrm{SRFE}_{i}}}{P_{\mathrm{obs}_{i}}}
$$

where $P_{\text {amount }}$ is the normalized amount of precipitation, and $P_{\mathrm{SRFE}}$ and $P_{\mathrm{obs}}$ are the SRFE and observed amount of precipitation per rainfall event, respectively.

The assessment of the number of rainy days per year was also normalized by comparing the number of observed rainy days (i.e., days with precipitation totals $>1 \mathrm{~mm})$ for each analytical year $\left(\overline{d_{\mathrm{obs}_{i}}}\right)$ and the corresponding SRFE estimation $\left(\overline{d_{\mathrm{SRFE}_{i}}}\right)$ as follows:

$$
F=\frac{1}{n} \sum_{i=1}^{n} \frac{\overline{d_{\mathrm{SRFE}_{i}}}}{\overline{d_{\mathrm{obs}_{i}}}}
$$

where $F$ is the normalized number of rainy days per year.

\section{2) LARGE-SCALE ANALYSIS}

Precipitation characteristics such as annual catchment totals, spatial patterns, and seasonality were validated on a subcatchment or river basin scale (for delineation of subcatchments, see Fig. 1). These spatial units are particularly relevant for these rainfall characteristics as they represent the conventional working units for hydrological applications. At the same time, and as suggested by Xie and Arkin (1995), aggregation on a larger scale enhances the stability of the precipitation validation exercise. The large-scale validation analysis was performed by comparing spatially aggregated SRFE cells belonging to each subcatchment or river basin against a corresponding interpolated rainfall field derived from ground observations.

As described by Goovaerts (2000), areal interpolation of precipitation can be enhanced if the kriging family of algorithms is employed. Kriging algorithms for spatial interpolation have been widely used and documented in the literature and, thus, they will not be discussed here. Instead we refer the reader to the works of Journel and Huijbregts (1978), Isaaks and Srivastava (1989), Goovaerts (1997), Burrough and McDonnell (1998), and Ly et al. (2011) for excellent reviews. In this study, we interpolate daily precipitation data available from the 205 gauge stations (see section 3) by using KED (Goovaerts 2000). KED takes advantage of one (or more) auxiliary variables to improve the spatial interpolation, which is particularly important in our validation study given the sparse data coverage in the study areas. As auxiliary variable to supplement daily rainfall records, we used high-resolution terrain elevation data provided by the NASA SRTM as the external drift in KED.

The spatial interpolation with KED was calculated on a daily time step for the 4-yr period (2003-06) and also for each spatial scale analyzed [i.e., pixel $\left(0.1^{\circ} \times 0.1^{\circ}\right)$, subcatchment, and river basin]. To automate the interpolation process we used the hydroTSM R package (http://CRAN.R-project.org/package=hydroTSM), which provides wrapper functions to different Kriging algorithms implemented in the automap (http://cran. r-project.org/web/packages/automap/automap.pdf) and 

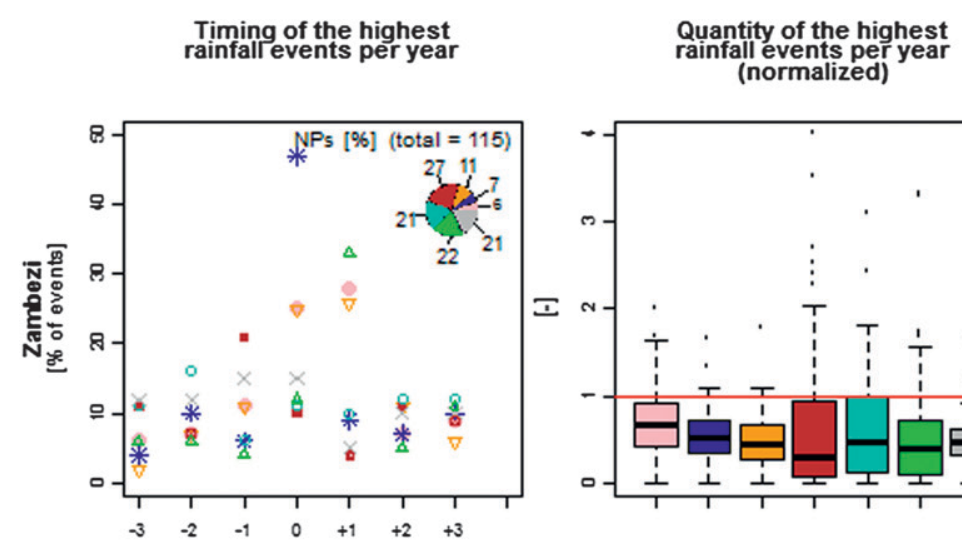

Number of rainy (normalized)
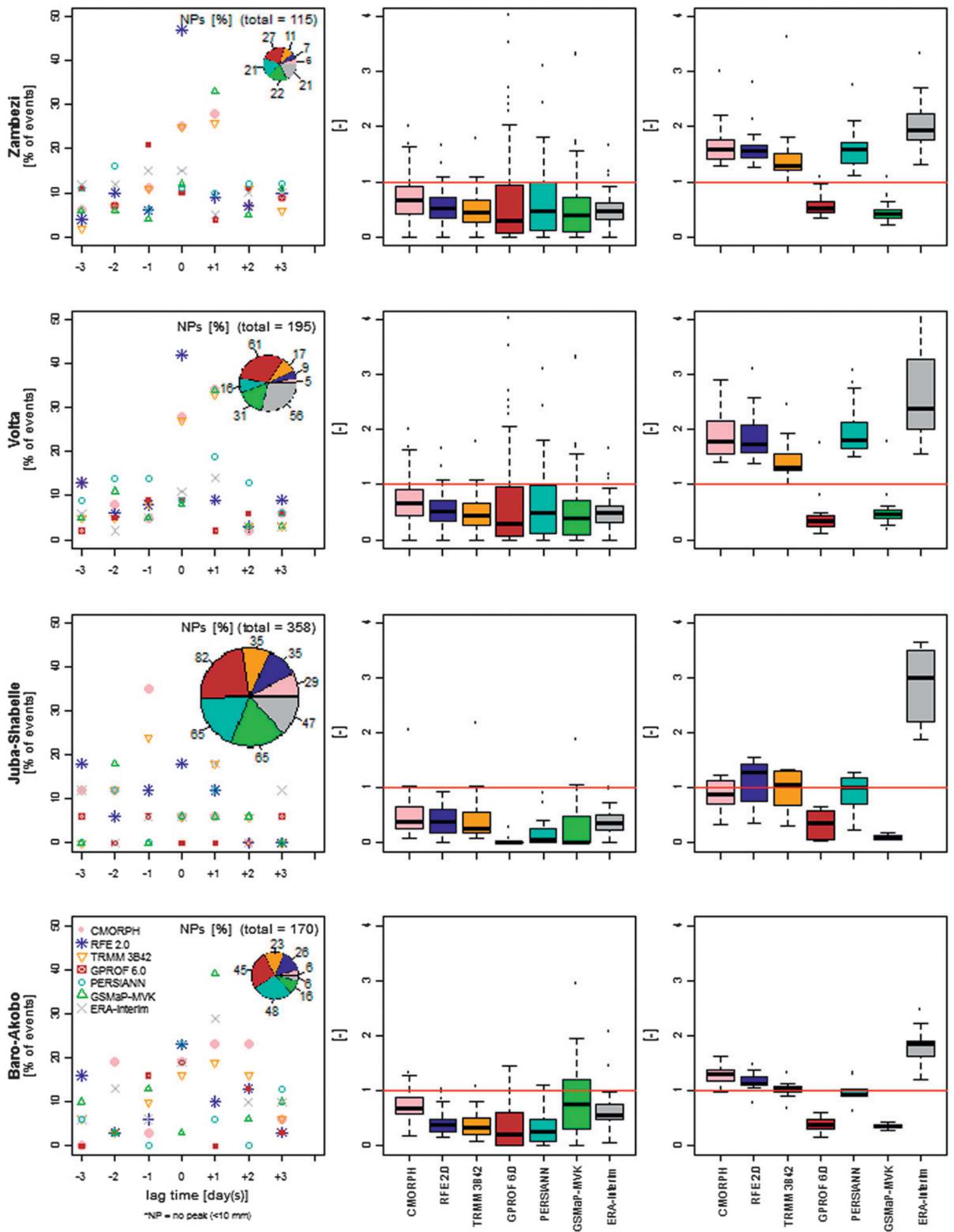

FIG. 3. Point-to-pixel analysis for each river basin (rows) for the different SRFE. (left) The percentage of the highest annual events with a lag time within $\left(t_{-3}, t_{+3}\right)$ and the number of NPs. A positive lag time means that the event was estimated later by the SRFE and vice versa for negative lag times. (middle) The normalized amount of rainfall for the highest rainfall events within $\left(t_{-3}, t_{+3}\right)$ [see Eq. (1)]. (right) The normalized number of rainy days per year (precipitation intensity $>1 \mathrm{~mm}$ ) [see Eq. (2)]. 
TABLE 3. Statistical measures of performance used for analysis on a subcatchment scale.

\begin{tabular}{|c|c|c|c|}
\hline Statistical measure & Equation & Optimum & Description/further information \\
\hline & $\sum^{N}\left(\mathrm{SRFE}_{i}-\mathrm{GO}_{i}\right)$ & \multirow[b]{2}{*}{0} & \multirow{5}{*}{$\begin{array}{l}\text { - Measures the average tendency of the satellite } \\
\text { estimates (SRFE) to be larger or smaller than } \\
\text { the average ground observations (GO). } \\
\text { - Positive or negative values indicate } \\
\text { overestimation or underestimation of the } \\
\text { observations, respectively. } \\
\text { - Measures the linear association between } \\
\text { ground observation and satellite estimation } \\
\text { while it is insensitive to bias. }\end{array}$} \\
\hline pBIAS (Yapo et al. 1996) & pBIAS $=100 \times \frac{i=1}{\sum_{i=1}^{N} \mathrm{GO}_{i}}$ & & \\
\hline & $\sum^{N}\left(\mathrm{GO}_{i}-\overline{\mathrm{GO}}\right)\left(\mathrm{SRFE}_{i}-\overline{\mathrm{SRFE}}\right)$ & \multirow{3}{*}{1} & \\
\hline$r$ & & & \\
\hline & $\begin{array}{r}N \times \sigma_{\mathrm{GO}} \times \sigma_{\mathrm{SRFE}} \\
\sum^{N}\left(\mathrm{SRFE}_{i}-\mathrm{GO}_{i}\right)^{2}\end{array}$ & & \\
\hline $\begin{array}{l}\mathrm{NS}_{\text {eff }}(\text { Nash and } \\
\text { Sutcliffe 1970) }\end{array}$ & $\mathrm{NS}_{\mathrm{eff}}=1-\frac{i=1}{\sum_{i=1}^{N}\left(\mathrm{GO}_{i}-\overline{\mathrm{GO}}\right)^{2}}$ & 1 & $\begin{array}{l}\text { - Determines the relative magnitude of the } \\
\text { residual variance compared to the variance of } \\
\text { the ground observations. Hence, it indicates } \\
\text { how well the plot of observed vs estimated data } \\
\text { fits the bisector line. } \\
\text { - Since this skill score is a composition of both } \\
\text { linear association and bias, it is a better score } \\
\text { than any of the above-mentioned individual } \\
\text { scores (Jobard et al. 2011). }\end{array}$ \\
\hline
\end{tabular}

the gstat (Pebesma and Wesseling 1998) R packages (http://www.R-project.org). KED interpolation was calculated with the following conditions: 1) a maximum distance of $500 \mathrm{~km}$ for spatial dependency; 2) automatic selection of the best variogram for each day, which was limited to the following theoretical models: spherical, exponential, Gaussian, and Matern Stein's parameterization; and 3) for the large-scale analysis the interpolated values in each cell are aggregated up to subcatchment and river basin scale.

\section{(i) Subcatchment}

Precipitation characteristics assessed at subcatchment scale are daily and monthly precipitation data, as well as seasonality. The performance of the different SRFE products was assessed through a series of statistical measures (see Table 3). These statistical measures summarize the strength of the relationship between daily SRFE values and their corresponding ground observations. Probability distributions, seasonality, and monthly characteristics (for wet and dry periods) are evaluated graphically using $Q-Q$ plots, average monthly precipitation graphs, and monthly boxplots, respectively (see Figs. 4-6 ).

(ii) Basin-scale analysis

Advanced hydrological applications increasingly rely on distributed models for which a correct spatial distribution of precipitation is essential. To assess the skills and accuracy of the SRFE products, the average annual precipitation was calculated for each grid cell as shown in Figs. 7 to 10 . The basin-scale analysis was completed by calculating the average annual catchment totals, standard deviation, and the distribution of annual bias.

\section{Results}

\section{a. Point-to-pixel analysis}

Results for the point-to-pixel comparison for each river basin are shown in Fig. 3. The plots for the Zambezi, Volta, and Baro-Akobo (see left-hand column of Fig. 3) show that most of the SRFE products captured most of the highest annual rainfall events with a lag time of 0 or +1 day, while for Juba-Shabelle most events were captured with a delay of 1 or 2 days. The number of NPs is notably lower in the Zambezi compared with the other basins, in particular against the Juba-Shabelle, which might be explained by morphoclimatic differences (it should be noted that, in order to allow a visual comparison, the relative sizes of the pie charts are proportional to the number of NPs). In the Zambezi basin, for example, precipitation falls over a large, flat (tropical wet) basin, and over relatively long time periods, thus explaining the low number of NPs and the increased number of fits (up to 1 day of lag time). By comparison, rainfall in the semiarid area of the Juba-Shabelle is less frequent and is strongly influenced by the winds of the ITCZ, which can present a problem for the SRFE algorithms.

When comparing the products, GPROF 6.0, PERSIANN, GSMaP-MKV, and, to a certain extent, ERA-Interim showed a very large number of NPs. In contrast, RFE 

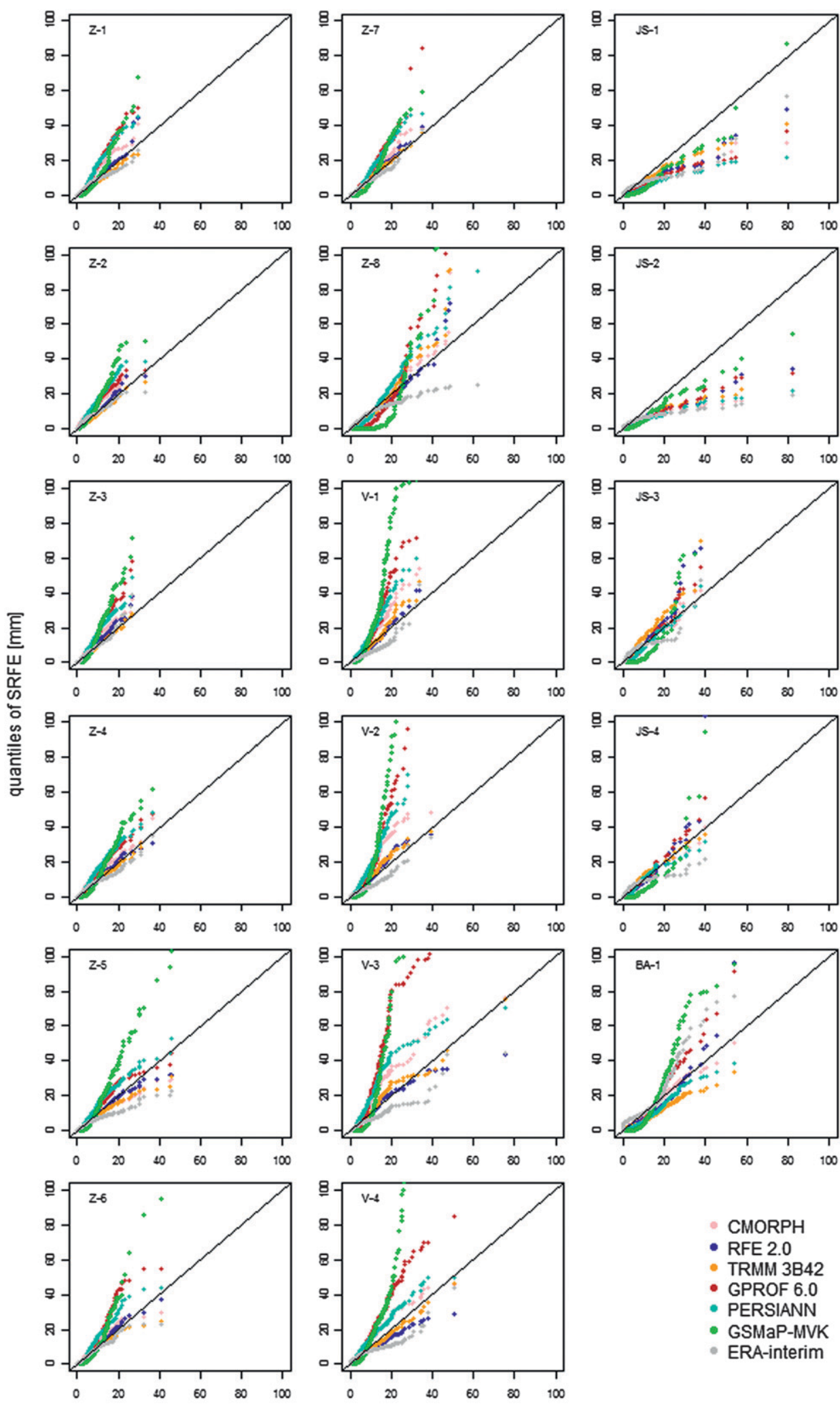

- CMORPH

- RFE 2.0

- TRMM 3B42

- GPROF 6.0

- PERSIANN

- GSMaP-MVK

- ERA-interim

quantiles of subcatchment interpolated rainfall [mm]

FIG. 4. $Q-Q$ plots of quantiles of subcatchment interpolated rainfall ( $x$ axis) vs SRFE quantiles ( $y$ axis) for each subcatchment analyzed. Any deviation from the bisector line indicates a distributional difference between both datasets. For the delineation of subcatchments see Fig. 1. Please note that the $y$ axes of panels labelled Z-8 and V-1 to V-4 are truncated at $100 \mathrm{~mm}$ to allow direct visual comparison. 

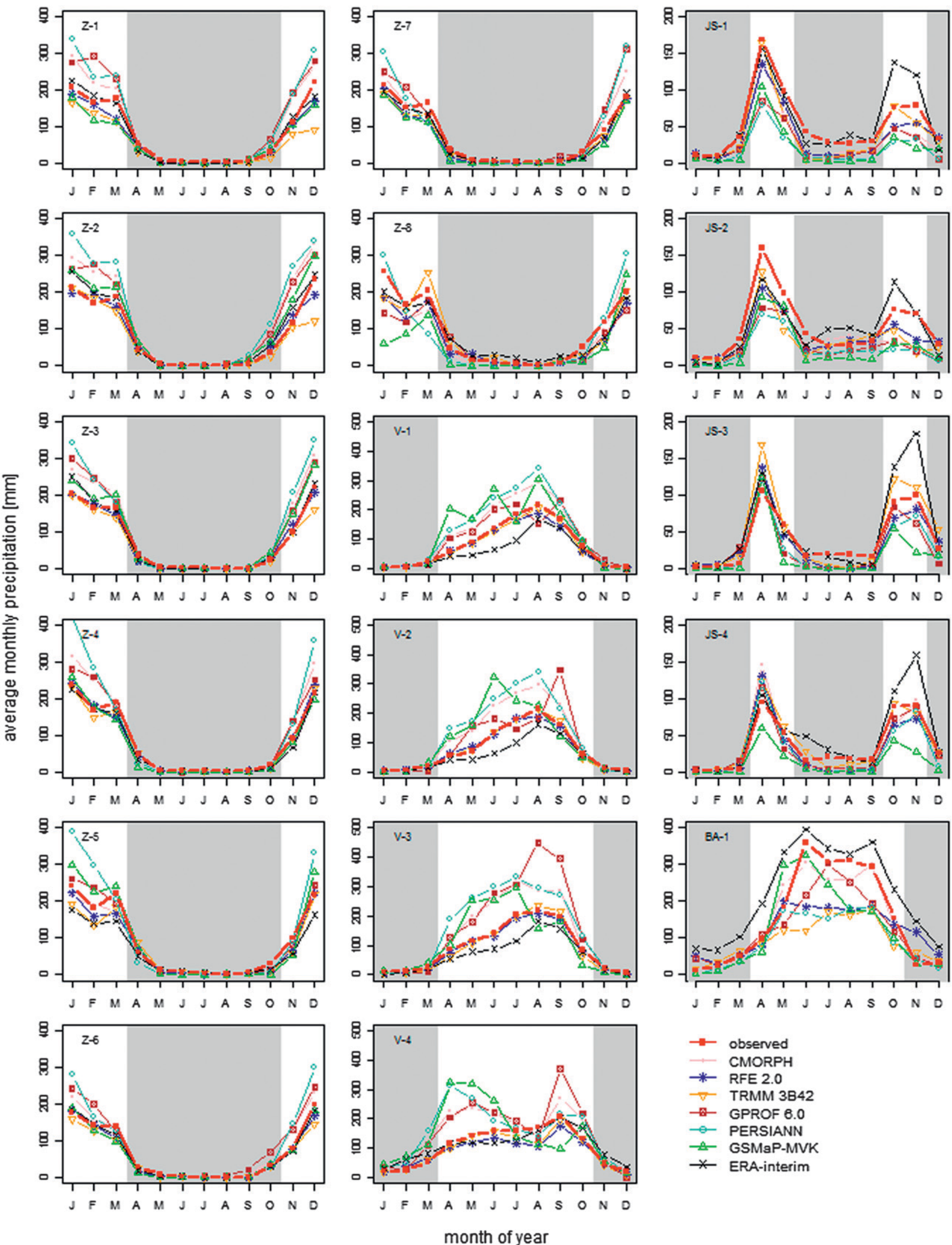

FIG. 5. Interannual variation of mean monthly precipitation for each subcatchment. In gray, the dry periods; in white, the wet periods according to Andah and Gichuki (2005), Artan et al. (2007), and Cohen Liechti et al. (2011). 

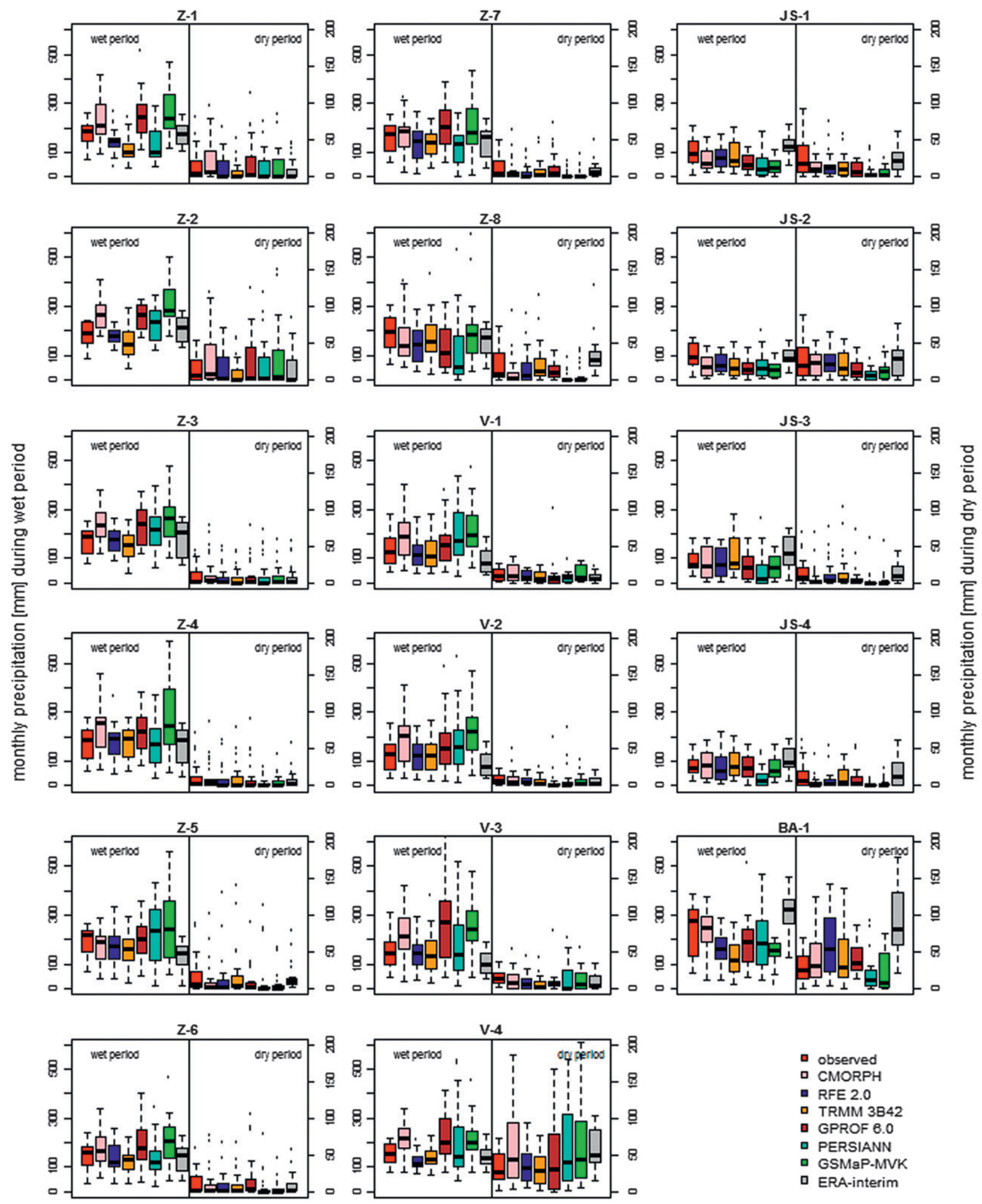

FIG. 6. Box-plot diagrams of monthly precipitation for each subcatchment. Note the different vertical axis scale for wet and dry periods. Wet and dry periods defined according to Andah and Gichuki (2005), Artan et al. (2007), and Cohen Liechti et al. (2011). 


\section{Zambezi}

a) interpolated observations

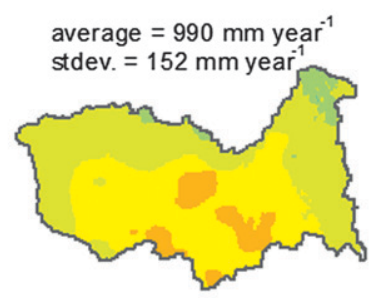

e) GPROF 6.0

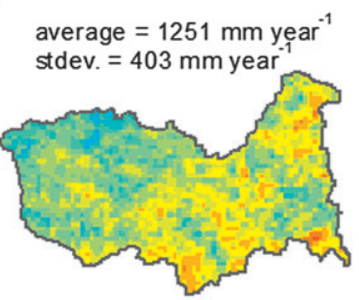

Mean annual precipitation [m m year ${ }^{-1}$ ]

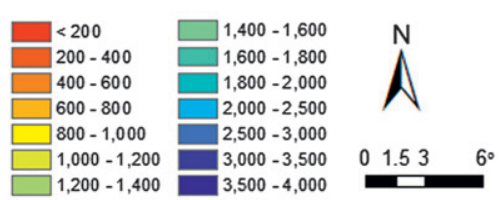

\section{b) CMORPH}

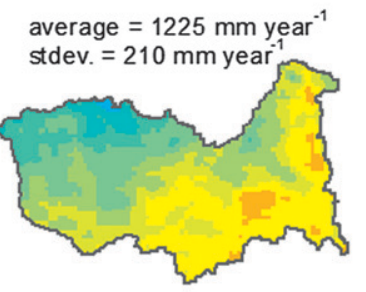

f) GSMaP-MKV

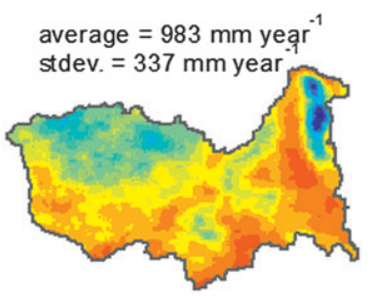

c) RFE 2.0

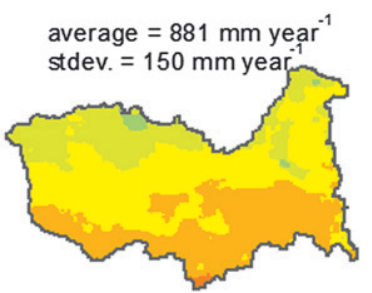

g) PERSIANN

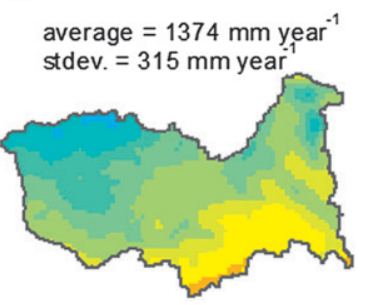

d) TRMM 3B42 v6

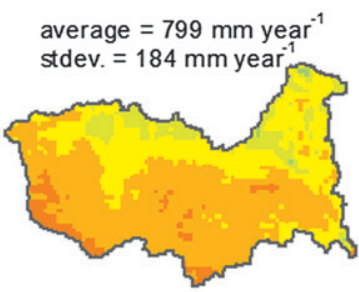

h) ERA-interim

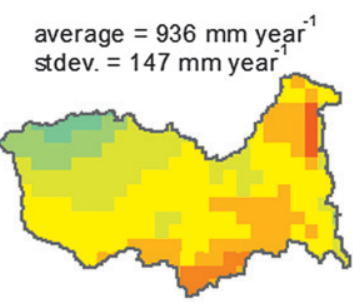

- CMORPH $\square$ PERSIANN

- RFE 2.0 a GSMaP-MVK

- TRMM 3B42 $\square$ ERA-interim

- GPROF 6.0

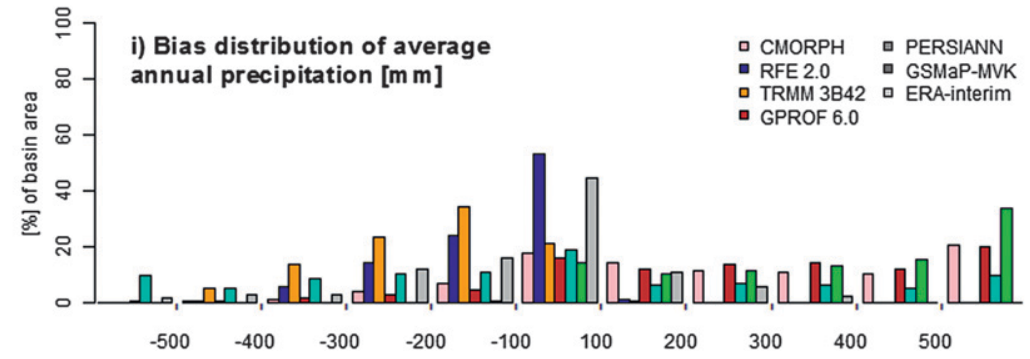

FIG. 7. Basin-scale analysis for the Zambezi. Maps show the mean annual precipitation supplemented with information about average basin total and average standard deviation. (i) The histogram shows the percentage of the basin area showing over- or underestimation of the average annual precipitation by a given amount.

2.0, followed by CMORPH and TRMM 3B42, showed both good timing for capturing the extreme precipitation events and a low number of NPs.

Results also show that all SRFE products underestimated the amount of precipitation during the heavy rainfall events regardless of the study area, with CMORPH slightly outperforming the other products (see middle column of Fig. 3). At the same time, most SRFE products overestimated the number of rainy days over tropical wet and dry zones (the Zambezi and Volta), while a mixed pattern was observed for semiarid or mountainous areas (Juba-Shabelle and Baro-Akobo) (see right-hand column of Fig. 3). Both GPROF 6.0 and GSMaP-MVK showed a persistent, basin-independent, underestimation of the number of rainy days, whereas ERA-Interim exhibited a persistent and significant overestimation. CMORPH, RFE 2.0, and PERSIANN showed comparable, moderate-to-good performances whereas TRMM 3B42 showed the best performance for all basins. For mountainous and semiarid areas, PERSIANN showed a performance comparable to TRMM 3B42, where the estimated data were in agreement with the observed rainy days.

\section{b. Subcatchment-scale analysis}

Table 4 shows the statistical measures of performance between the daily SRFEs and observed precipitation values for each subcatchment (note that all acronyms are expanded in the appendix).

PBIAS shows a diverse picture for each river basin. A significant variability among the SRFE and subcatchments can be seen for the Zambezi basin whereas, for the Volta, overestimation of daily precipitation ranged from $+20 \%$ to $+71 \%$ for most products. For both basins, RFE 2.0, TRMM 3B42, and ERA-Interim showed the lowest bias. For the Juba-Shabelle, a persistent underestimation (between $-11 \%$ and $-65 \%$ ) was observed, whereas ERA-Interim showed the smallest bias between $-5 \%$ and $+34 \%$. For the Baro-Akobo, most satellite products underestimated daily rainfall by circa $-20 \%$ to $-30 \%$, while ERA-Interim showed a considerable overestimation of $+44 \%$.

The correlation coefficient $(r)$ also exhibited productand basin-specific tendencies. The respective correlations of CMORPH, RFE 2.0, TRMM 3B42 and ERA-Interim were comparatively higher than those of the remaining 


\section{Volta}

a) interpolated observations

average $=1117 \mathrm{~mm}$ year $^{-1}$ stdev. = $124 \mathrm{~mm}_{\text {year }}{ }^{-1}$

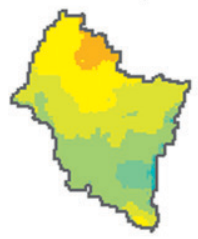

e) GPROF 6.0

average $=1469 \mathrm{~mm}$ year $^{-1}$ stdev. $=610 \mathrm{~mm} \mathrm{year}^{-1}$

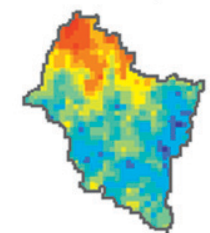

Mean annual precipitation [mm year-1]

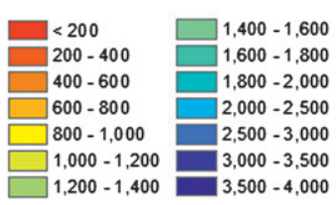

b) CMORPH

average $=1530 \mathrm{~mm}$ year $^{-1}$ stdev. $=263 \mathrm{~mm}_{\text {year }}{ }^{-1}$

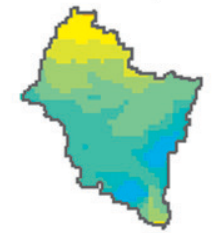

f) GSMaP-MKV

average $=1476 \mathrm{~mm}$ year $^{-1}$ stdev. $=379 \mathrm{~mm}$ year $^{-1}$

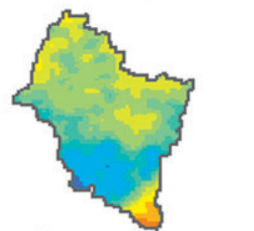

C) RFE 2.0

average $=957 \mathrm{~mm}_{\text {year }^{-1}}$ stdev. $=105 \mathrm{~mm}_{\text {year }}$

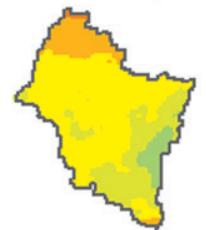

g) PERSIANN

average $=1663 \mathrm{~mm}_{\text {year }}{ }^{-1}$ stdev. $=227 \mathrm{~mm}$ year

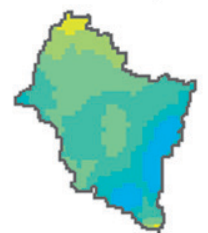

d) TRMM 3B42 v6

average $=997 \mathrm{~mm}$ year $^{-1}$ stdev. $=141 \mathrm{~mm}$ year $^{-1}$

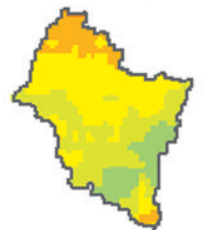

h) ERA-interim

average $=871 \mathrm{~mm}$ year $^{-1}$ stdev. $=63 \mathrm{~mm}$ year $^{-1}$

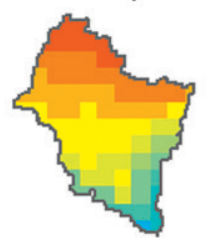

- CMORPH a PERSIANN

- RFE 2.0 a GSMaP-MVK

- TRMM 3B42 $\square$ ERA-interim

a GPROF 6.0

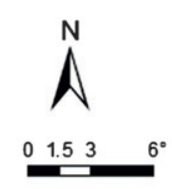

Bias distribution of average

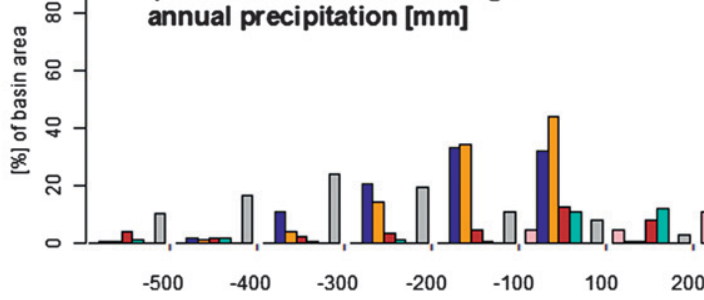

FIG. 8. As in Fig. 7, but for the Volta.
SRFEs. For GPROF 6.0, this might be explained by the refilling of the time series using information from the previous day, although for GSMaP-MKV it could be a result of the inherent limitations of the product [see section 2b(2)(vi)]. The Zambezi and Volta basins showed higher correlations compared with the Juba-Shabelle and Baro-Akobo basins, which might be caused by morphoclimatic differences between both pairs of basins.

$\mathrm{NS}_{\text {eff }}$ showed the accuracy of the SRFE products in replicating observed (interpolated) precipitation. RFE 2.0, TRMM 3B42, and ERA-Interim were notably the more accurate products for the Zambezi, as was RFE 2.0 for the Volta. GPROF 6.0, PERSIANN, and GSMaPMVK were no more accurate than the average interpolated daily rainfall data (i.e., $\mathrm{NS}_{\text {eff }}<0$ ). None of the products showed a satisfactory $\mathrm{NS}_{\text {eff }}$ for either JubaShabelle or Baro-Akobo, which might be due to the significant interpolation variances in these areas.

A comparison between the probability distributions of the SRFE and the daily interpolated rainfall data is presented in Fig. 4. Four general trends can be seen: 1) good agreement for the lower precipitation values $(<15 \mathrm{~mm})$; 2 ) significant dispersion for higher precipitation values, indicating increased uncertainty in the estimation of higher-end percentiles; 3) persistent overestimation of precipitation by GPROF 6.0 compared to the other products; and 4) tendency of GSMaP-MVK to underestimate observed values in the lower range while shifting toward extreme overestimation for higher-range values. Basinwide, RFE 2.0 and TRMM 3B42 showed good correspondence with the observed precipitation data, with the largest spread amongst SRFE products observed for the Volta and Baro-Akobo basins.

For the Volta, PERSIANN and CMORPH showed an overestimation of heavy precipitation in northwestern areas (V-1 to V-3) and good agreement for the coastal area (V-4), whereas the opposite can be seen for TRMM 3B42 and RFE 2.0. A large overestimation is also observed for GSMaP-MKV and GPROF 6.0 across the whole Volta basin, particularly at higher quantiles. General underestimation for all products is evident in the Ethiopian highlands (JS-1 to JS-2), while for coastal areas (JS-3 and JS-4) CMORPH and PERSIANN replicated the observed distribution relatively well.

Seasonal deviations of the SRFE are depicted in Fig. 5. In general, results during the dry period were 


\section{Juba-Shabelle}

\section{a) interpolated observations}
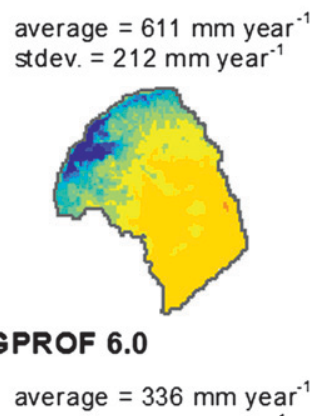
stdev. $=178 \mathrm{~mm}_{\text {year }}{ }^{-1}$

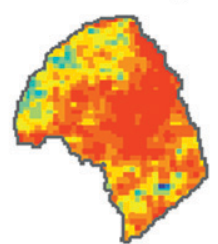

Mean annual precipitation [m m year ${ }^{-1}$ ]

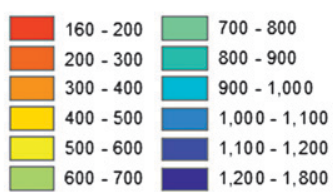

e) GPROF 6.0

\section{b) $\mathrm{CMORPH}$}

average $=406 \mathrm{~mm}$ year $^{-1}$ stdev. $=99 \mathrm{~mm}_{\text {year }}{ }^{-1}$

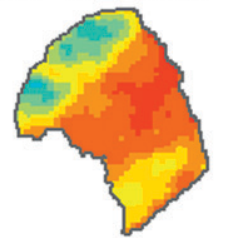

f) GSMaP-MKV

average $=246 \mathrm{~mm}_{\text {year }}{ }^{-1}$ stdev. $=176 \mathrm{~mm}_{\text {year }}{ }^{-1}$

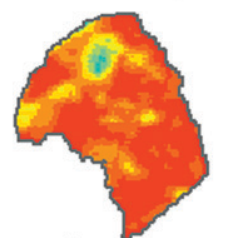

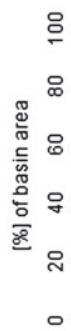

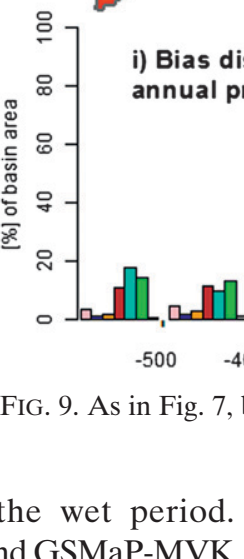

CMORPH, GPROF 6.0, PERSIANN, and GSMaP-MVK most notably showed large, positive deviations whereas TRMM 3B42 and RFE 2.0 were the most accurate. Over mountainous areas (BA-1, JS-1, and JS-2), RFE 2.0 and ERA-Interim diverged from their prevailing tendencies and showed underestimation and overestimation of observed precipitation, respectively. All SRFE products replicated the bimodal precipitation pattern over the Juba-Shabelle with (expected) large deviations around the monthly maximum. In turn, the slightly bimodal precipitation pattern observed over the oceanic-influenced area south of the Volta (V-4) was closely replicated by RFE 2.0, TRMM 3B42, and ERA-Interim, with the remaining SRFE products failing to produce such a pattern.

The statistics of monthly precipitation during wet and dry periods are summarized graphically in Fig. 6. This figure confirms the general tendencies shown in Fig. 5. In particular, large variability is observed for the wet period in the Zambezi, with CMORPH, GPROF 6.0, and GSMaPMKV overestimating rainfall and TRMM-3B42 slightly underestimating rainfall in most of the subcatchments c) RFE 2.0

average $=444 \mathrm{~mm}_{\text {year }}{ }^{-1}$
stdev $=159 \mathrm{~mm}$ year $^{-1}$

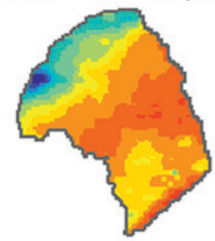

g) PERSIANN

average $=272 \mathrm{~mm}$ year $^{-1}$ stdev. $=94 \mathrm{~mm}^{-1}$ year $^{-1}$

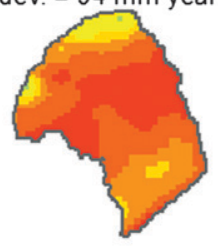

d) TRMM 3B42 v6

average $=469 \mathrm{~mm}$ year $^{-1}$ stdev. $=174 \mathrm{~mm}$ year $^{-1}$

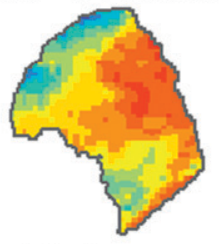

h) ERA-interim

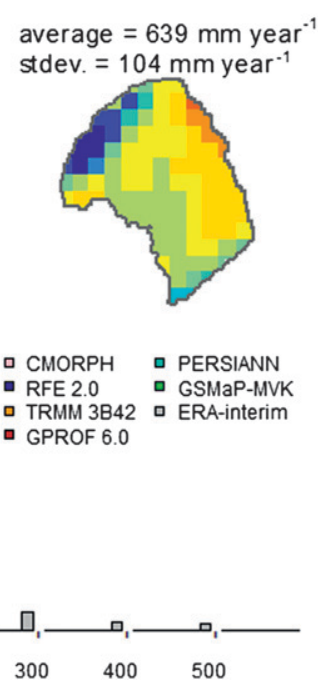

average $=639 \mathrm{~mm}$ year $^{-1}$ ev. $=104 \mathrm{~mm}^{2}$ year

CMORPH PERSIANN - RFE 2.0 aSMaP-MVK 口 TRMM 3B42 ם ERA-interim GPROF 6.0 


\section{Baro-Akobo}

a) interpolated observations

average $=2009 \mathrm{~mm}$ year $^{-1}$ stdev. $=167 \mathrm{~mm}$ year $^{-1}$

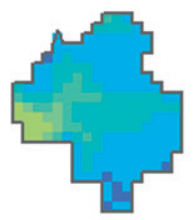

e) GPROF 6.0

average $=1498 \mathrm{~mm}$ year $^{-1}$ stdev. $=435 \mathrm{~mm}$ year $^{-1}$

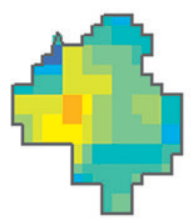

Mean annual precipitation [m m year ${ }^{-1}$ ]

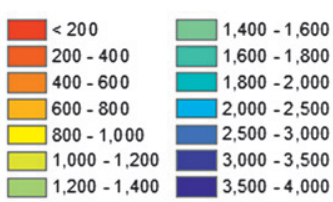

\section{b) CMORPH}

average $=1791 \mathrm{~mm}$ year $^{-1}$ stdev. $=213 \mathrm{~mm}$ year $^{-1}$

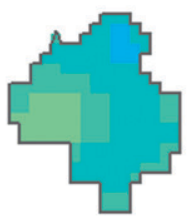

f) GSMaP-MKV

average $=1473 \mathrm{~mm}$ year $^{-1}$ stdev. $=359 \mathrm{~mm}$ year $^{-1}$

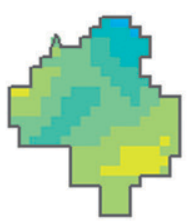

c) RFE 2.0

average $=1460 \mathrm{~mm}$ year $^{-1}$ stdev. $=299 \mathrm{~mm} \mathrm{year}^{-1}$

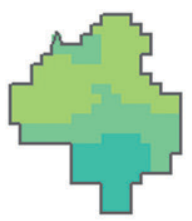

g) PERSIANN

average $=1133 \mathrm{~mm}_{\text {year }}{ }^{-1}$ stdev. $=102 \mathrm{~mm}$ year $^{-1}$

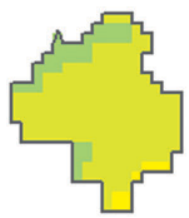

d) TRMM 3B42 v6

average $=1128 \mathrm{~mm}_{\text {year }}{ }^{-1}$ stdev. $=292 \mathrm{~mm} \mathrm{year}^{-1}$

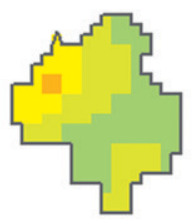

h) ERA-interim

average $=2653 \mathrm{~mm}_{\text {year }}{ }^{-1}$ stdev. $=126 \mathrm{~mm}$ year $^{-1}$
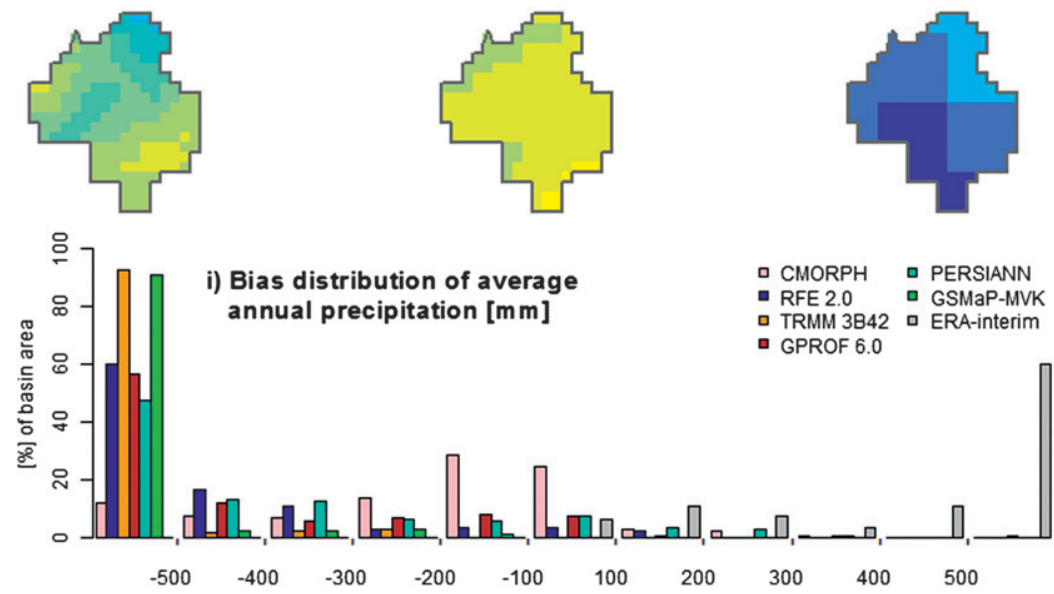

FIG. 10. As in Fig. 7, but for Baro-Akobo. season. Underestimation decreased in downstream areas (JS-3 and JS-4), where the median was well captured although the spread was mostly overestimated. The dry season shows a more homogeneous pattern over the Juba-Shabelle basin, with only ERA-Interim closely resembling the observations. All other SRFE products underestimated the observations.

Results for the Baro-Akobo basin show a significant overestimation of precipitation by ERA-Interim for both wet and dry seasons, while the large underestimation of RFE 2.0 (see Fig. 5) applies to the wet period only. A similar pattern can be seen for TRMM 3B42 and GPROF 6.0. Finally, the previously noted overall superior performance of CMORPH in Baro-Akobo (see, e.g., Table 4 and Figs. 4 and 5) is explained by its ability to correctly estimate monthly precipitation during wet periods, as the performance of CMORPH during dry periods is similar to that of TRMM 3B42 and GPROF 6.0.

\section{c. Basin-scale analysis}

The spatial distribution of annual precipitation patterns are shown for each basin and each product in
Figs. 7-10 and are analyzed individually for each basin below.

\section{1) ZAMBEZI RIVER BASIN}

In the Zambezi basin, (interpolated) observed annual precipitation (Fig. 7a) shows a decrease from both the northwest and the northeast toward the central south, varying from 1000 and $1400 \mathrm{~mm}$ in the wetter northern areas to $600 \mathrm{~mm}$ in the drier southern areas. This is in full agreement with the findings by Shahin (2002). RFE 2.0 (Fig. 7c) and TRMM 3B42 (Fig. 7d) closely replicated the observed spatial pattern, showing a slight underestimation of $-11 \%$ and $-19 \%$, respectively. For both products, precipitation ranged between 600 and $1400 \mathrm{~mm}$. In turn, ERA-Interim (Fig. 7h) estimated the spatial patterns reasonably well, ranging between 200 and $1800 \mathrm{~mm}$ with a slight overestimation over the western area and an underestimation over the southern and eastern areas. Figure $7 \mathrm{i}$ showed that underestimation of RFE 2.0, TRMM-3B42, and ERAInterim was mainly restricted to relatively small deviations (typically up to $300 \mathrm{~mm} \mathrm{yr}^{-1}$ ). In contrast, 


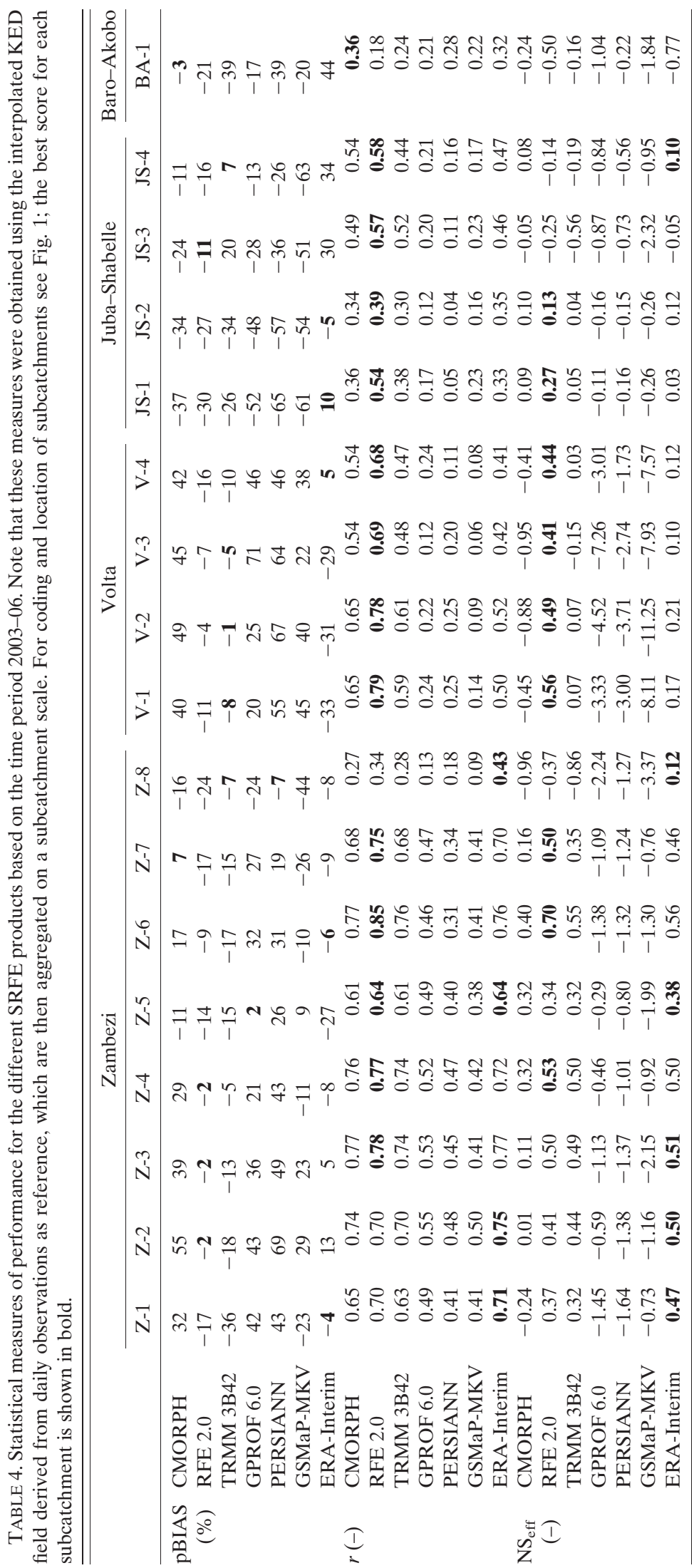


CMORPH, GPROF 6.0, and PERSIANN (Figs. 7b,e,g) showed a significant overestimation that was mainly concentrated in the western part of the basin, whereas for GSMaP-MKV (Fig. 7f) over- and underestimations compensate each other. These latter four SRFE products showed the poorest agreement with the observations with average annual precipitation being overestimated by more than $500 \mathrm{~mm} \mathrm{yr}^{-1}$ in up to $30 \%$ of the basin's area.

\section{2) Volta RIVER BASIN}

Interpolated precipitation in the Volta basin (Fig. 8a) showed an increasing gradient from the dry north $(600 \mathrm{~mm})$ to the wet south $(1600 \mathrm{~mm})$, ending in an abrupt reduction in precipitation $(1000 \mathrm{~mm})$ at the coastal zone. This pattern fully agrees with the literature (Shahin 2002). Within this basin RFE 2.0 and TRMM $3 B 42$ (Figs. 8c and 8d) corresponded well with the (interpolated) observed precipitation, exhibiting a slight underestimation of $-14 \%$ and $-11 \%$, respectively. ERA-Interim (Fig. 8h) showed a gradual increase of precipitation from north to south, although it failed to capture the decline in observed precipitation at the coast. ERA-Interim showed an underestimation of $-22 \%$ throughout the basin. CMORPH, GPROF 6.0, GSMaP-MKV, and PERSIANN (Figs. 8b,e-g) all showed significant precipitation overestimation, with up to $70 \%$ of the basin overestimated by more than $500 \mathrm{~mm} \mathrm{yr}^{-1}$ (see Fig. 8i). RFE 2.0 and TRMM-3B42 showed the lowest error with a difference of approximately +100 to $-200 \mathrm{~mm} \mathrm{yr}^{-1}$ in $\sim 80 \%$ of the area, compared to the observed precipitation.

\section{3) JubA-Shabelle RiVERS BASIN}

The spatial rainfall pattern in the Juba-Shabelle basin follows the orography (see Fig. 9a), with rainfall over the lowlands $(400-500 \mathrm{~mm})$ steadily increasing toward the Ethiopian highlands (up to $1800 \mathrm{~mm}$ ). In Fig. 9h it can be seen that ERA-Interim closely estimated the interpolated observations (Fig. 9a) in terms of precipitation range, spatial pattern, and areal average. However, a previous study suggests average annual precipitation to be closer to $500 \mathrm{~mm}$ with a high spatial variability between the Ethiopian highlands $(1300 \mathrm{~mm})$, the lowlands $(200 \mathrm{~mm})$, and the coastal zone $(500 \mathrm{~mm})$ (Artan et al. 2007), it seems reasonable to suggest that RFE 2.0 (Fig. 9c) and TRMM 3B42 (Fig. 9d) more closely estimated the observed pattern. Both products captured the arid conditions over the lowlands (200$400 \mathrm{~mm}$ ) and the basin average well, showing a slight underestimation over the Ethiopian highlands, which is probably a result of the low number of observation networks in this area. The remaining products (Figs. 9b, e-g) showed a significant underestimation and poor correspondence with the interpolated observations. However, it should be noted that, for this basin, deviations do not prevail in the extreme range (see Fig. 9i).

\section{4) BARO-AKOBO RIVERS BASIN}

For the Baro-Akobo basin, interpolated observed rainfall data (Fig. 10a) showed a minimum precipitation of $1400 \mathrm{~mm}$ in the west (river mouth), which increases to up to 2200 and $2600 \mathrm{~mm}$ in the north and southeast areas, respectively. This pattern agrees with the literature (e.g., Romilly and Gebremichael 2011). Figure 10 shows that deviations from the observations vary between products, with no single product outperforming the rest. Considering average annual basin precipitation, underestimation of the observed values varied between $56 \%$ (Fig. 10g) and 89\% (Fig. 10b). In contrast, ERAInterim (Fig. 10h) showed a significant overestimation of between 2200 and $3500 \mathrm{~mm}$ (32\% of the observed average value). The majority of the SRFE products underestimated the observed values by more than $500 \mathrm{~mm} \mathrm{yr}^{-1}$ over large areas of the basin (see Fig. 10i) although, in contrast, ERA-Interim overestimated the observations. CMORPH produced no extreme deviations and, although it estimated the observed data only moderately well (see Fig. 10b), it appeared to be the best performing product overall.

\section{Discussion and conclusions}

\section{a. General features}

While each SRFE has its own strengths and limitations according to the temporal and spatial scale as well as the geographical location, eight general features, discussed hereafter, were observed.

\section{1) ABILITY TO ESTIMATE PRECIPITATION DURING THE DRY SEASON ON A MONTHLY BASIS}

Accurate estimation of the lower-range rainfall amounts (see Fig. 4) and reduced variability between the SRFE products (see Fig. 5) was observed during the dry season. During the dry period rainfall occurrence is mostly restricted to light rain, which might explain the accurate agreement between products and observations for this season. Accurate detection of light rainfall events by different SRFE products was previously reported by Symeonakis et al. (2009).

\section{2) General underestimation of HeAvy RAINFALL EVENTS}

Although the timing of heavy rainfall events was properly captured by most SRFE products, the amount of rainfall was underestimated (see Fig. 3). There may 
be a number of reasons for this fact, but the small extent of the heavy precipitating cells, which is generally below the detection limit of the PMW satellite sensors, is potentially the most relevant. Another potential cause is the unreliable calibration of the retrievals for extreme values.

\section{3) ABILITY TO REPLICATE BIMODAL ANNUAL PRECIPITATION PATTERNS}

A good replication of bimodal patterns over the JubaShabelle basin and the coastal zone of the Volta basin was observed (see Fig. 5). In the Juba-Shabelle basin a large variation for the wet seasons was observed, whereas a noticeable variability was observed for the dry season in the oceanic-influenced coastal zone of the Volta basin (V-4).

4) SUPERIOR PERFORMANCE OVER THE TROPICAL WET AND DRY ZONES (ZAMBEZI AND VOLTA) THAN OVER SEMIARID AND MOUNTAINOUS REGIONS (JUBA-SHABELLE AND BARO-AKOBO)

The differences in overall performance of the SRFEs over the different catchments are most likely explained by morphoclimatic differences. The influence of orography on precipitation itself is currently an important research topic in atmospheric science, but no accurate representation of rainfall structure in the study areas is yet available. However, complex orography and sparse ground observations from the Juba-Shabelle basin make it difficult to compare interpolated KED fields with SRFE data. Nevertheless, it should be noted that SRFEs are, in general, more suited to estimating convectional tropical rainfall patterns than isolated convection in semiarid to arid areas which are more difficult to capture owing to factors such as subcloud evaporation, rainfall suppression by desert aerosols, and hot background surfaces (Dinku et al. 2010a).

\section{5) INCREASING UNCERTAINTY IN THE ESTIMATION OF HIGHER-END PERCENTILES OF DAILY PRECIPITATION}

While the discrimination between rain and no rain is relatively reliable using satellite sensors, quantitative estimation remains challenging (Dinku et al. 2010b). The increase in uncertainty observed in this work could be related to the fact that spatial scale usually decreases with increasing amount of precipitation and hence precipitation might fall below the detection limit of the satellite PMW sensors or it may be ascribed to the information content of IR data in general (Dinku et al. 2007; Xie and Arkin 1995).

\section{6) LOW ACCURACY IN DETECTING HEAVY RAINFALL EVENTS OVER SEMIARID AREAS}

A higher number of NPs were found for the JubaShabelle compared to the other basins (see Fig. 3). This indicates a particular weakness in detecting the rainfall signal in this basin. Since all the gauge stations used for the point-to-pixel analysis were located in the semiarid area and none in the Ethiopian highlands, such weakness is likely linked to climatological rather than topographic features. This is supported by Dinku et al. (2010a), who reported a decreasing probability of detection with increasing aridity.

\section{7) OVERESTIMATION OF NUMBER OF RAINY DAYS OVER TROPICAL WET AND DRY ZONES (ZAMBEZI AND VOLTA)}

A considerable overestimation was observed for all products with the exception of GPROF 6.0 and GSMaPMKV. This overestimation can be partially explained by differences in how the sensors and SRFEs interpret light rainfall events-for example, not clearly discriminating between "drizzly days" and "rainy days."

\section{8) Performance over subcatchments} INCLUDING THE RIVER MOUTH (V-4 AND Z-8) IS SOMEWHAT WEAKER THAN THAT OF OTHER SUBCATCHMENTS IN THE SAME BASIN

Current results do not allow for advancing any final explanation of this finding, but it appears that the topographical discontinuity at the coast may play a role in determining changes in the precipitation regime that influences the retrievals. Indeed, retrieval algorithms for coastal areas normally divide into two versions: one for the land and one for the sea (i.e., one using the scattering and the other the emissions in the PMW), thereby creating potential problems in merging the two retrieval types.

\section{b. Product ranking}

In general, GPROF 6.0 and GSMaP-MVK gave the weakest performance in this study. Both products were outperformed in most of the evaluation aspects, showing, as the main weaknesses, a large underestimation of number of rainy days per year and a significant overestimation of monthly (and annual) precipitation. This suggests that daily rainfall variability is not estimated well by these products, with a large number of rain-free days and only a few days featuring extreme rainfall events. Furthermore, the large number of "NPs" for both products indicates that the few days for which GPROF 6.0 and GSMaP-MVK show extreme precipitation do not conform temporally to the observations. Finally, GPROF 6.0 
shows an evident scattered spatial distribution of average annual rainfall over all basins that, for most cases, do not follow observed patterns. The large positive bias of GPROF 6.0 and the low detection probability of GSMaPMVK have been reported in previous studies over Africa (Dinku et al. 2010b; Jobard et al. 2011). The reason behind these shortcomings might be due to the difficulty in selecting the correct rainfall profile for the cloud, thus resulting in a nonsatisfactory representation of the physics involved in retrieval. This is a known limitation of statistical-physical rainfall retrieval algorithms given that an observed PMW brightness temperature profile can be associated with several cloud profiles from the cloudradiation database. The new parametric algorithms for the Global Precipitation Measurement Mission aim to improve this problem using an onboard calibration with the dual-frequency radar.

Results for PERSIANN show large quantitative deviations of monthly and annual values that confirm most previous studies. Depending on the morphoclimatic zones analyzed, these deviations are either over- or underestimations of the observations with no distinct pattern. Overestimation is particularly evident over the tropical wet and dry zones (Zambezi and Volta), with extreme deviations (up to $1500 \mathrm{~mm} \mathrm{yr}^{-1}$ ) resulting from overestimation of both rainy days per year and daily precipitation (see Figs. 3 and 4). The intraseasonal comparison showed that the bias is mostly confined to the rainy season. Similar results were shown by other authors over Uganda (Asadullah et al. 2008), India (Brown 2006), Colombia (Dinku et al. 2010b), Australia, and parts of Asia (Sorooshian et al. 2000), with the main reason for the bias being the lack of calibration against ground data. In contrast, underestimation of observed precipitation is most notable over mountainous regions with relatively warm clouds (Ethiopian highlands). Romilly and Gebremichael (2011) suggested that this underestimation could be linked to either poor detection of light rain or underestimation of total precipitation at high altitudes as a result of the thermal IR thresholds that discriminate between raining and nonraining clouds (Cattani et al. 2009). In this present work, the detectability of rainfall does not seem to be the problem as the number of rainy days is well captured for the BaroAkobo and Juba-Shabelle, while the ability to correctly quantify precipitation is clearly limited because monthly and event-based precipitation is mostly underestimated.

The ERA-Interim reanalysis product showed good correspondence with observed values for intraseasonal variability as well as for spatial distribution over the tropical wet and dry zones. Over the mountainous areas in Ethiopia a clear overestimation of observed precipitation was given, which is in full agreement with the findings of Maidment et al. (2010). ERA-Interim showed a persistent overestimation of light rainfall events but an underestimation of heavy rainfall occurrences (see Figs. 3 and 4). This indicates that precipitation is represented very smoothly, meaning many days with precipitation values below $10 \mathrm{~mm}$ and only a limited number of days with heavier rainfall. This agrees with the findings of Ailliot et al. (2011). Such precipitation estimate behavior might be explained by the spatial scale of the input data used by ERA-Interim. The weather model uses information at a synoptic scale, which does not capture small-scale and rapidly moving variations (e.g., storm cells) and, thus, they might be smoothed out (Ailliot et al. 2011). This feature is extremely important when daily hydrological applications, such as flood forecasting, are calculated as the effect may propagate in time.

CMORPH showed a variable performance over the study areas. In areas such as Volta and (partly) Zambezi, a tendency to overestimate the amount of precipitation during wet periods, as well as the number of rainy days per year, was observed, which agrees with the findings of Romilly and Gebremichael (2011). Both areas are influenced by the ITCZ where a deep layer of convection leads to an increase in airborne ice particles, which are perceived as precipitation by PMW sensors (Nesbitt et al. 2008), and could, therefore, explain the overestimation of observed precipitation. Although calibration against ground observations might be able to mitigate this effect, this is not part of the current algorithm although it is expected for future versions (Xie et al. 2011). Comparatively, CMORPH showed a superior ability to replicate daily, monthly, and annual precipitation over mountainous areas (BA-1), which is in full agreement with the findings of Romilly and Gebremichael (2011) and Dinku et al. (2007). The distribution of daily rainfall together with the intraseasonal and spatial distribution patterns of observed precipitation was remarkably well replicated. A possible explanation for CMORPH's ability to capture orographic enhanced rainfall can be found in the structure of the algorithm, which is essentially an interpolator of PMW-derived rainfall fields. In other words, CMORPH with its propagation of rainfall fields takes care of the temporal evolution of orographic effects, although it does not contain cloud evolution parameters.

The best performance results were obtained for RFE 2.0 and TRMM 3B42. Unlike the other products, both captured the intraseasonal variability well for most study areas even during wet periods. The spatial distribution pattern and the average annual precipitation were generally in agreement with the observations and notably outstanding for the tropical wet and dry zone. 
The timing of the highest annual precipitation events were identified with a maximum discrepancy of \pm 1 day. It is plausible that the accurate performance of these two products is linked to their embedded bias correction that relies on rain gauge network data. Deficiencies of these products were mostly found over mountainous areas, in which precipitation was generally underestimated, confirming results by Dinku et al. (2007). For RFE 2.0 this can be explained by the lack of orographic enhanced rainfall effects within the algorithm. The GPI data (Arkin et al. 1994), on which RFE 2.0 relies to estimate precipitation, are known to underestimate rainfall over mountainous and coastal regions of Africa (Herman et al. 1997). Over regions with a dense GTS network this effect is mitigated through local calibration. In mountainous areas, however, the station network density is sparse resulting in increased deviations and stresses the importance of local calibration (Stisen and Sandholt 2010).

We must stress, however, that this ranking is not absolute as different intercomparison exercises may result in a different rank according to the performance of the respective products under different conditions (Adler et al. 2001; Ebert et al. 1996; Smith et al. 1998). For example, data availability and/or spatial scale may affect the assessment of SRFE performance. However, considering the current data availability, these results provide a valuable insight for the hydrological and meteorological community on the relative quality of SRFE products over different African river basins. These findings will contribute to 1) enhancing the confidence and use of such products within hydrological applications and 2) making more informed decisions about a suitable SRFE for given morphoclimatic zones in Africa.

\section{c. Final conclusions and recommendations}

It may be argued that the superior performance of RFE 2.0 and TRMM 3B42 is due to the fact that they do ingest gauge data for bias correction, whereas the remaining SRFE products do not. However, it has to be emphasized that $79 \%$ of the daily data used for validation are non-GTS station data that are not available for the correction of these products. Consequently, we could argue that a small amount of daily data used for bias correction may significantly increase the performance of these products compared to their noncorrected counterparts.

Further, it can be argued that discrepancies between SRFE and ground observations might be attributed to shortcomings in the observational datasets and, thus, not entirely attributable to the products themselves. Given the nature of the ground observations used within this study (i.e., multiple data sources-e.g., GTS and not fully verifiable non-GTS), inconsistencies in the 24-h reference period for measuring the rainfall may appear. Therefore, results for lag times less than 1 day may contain relevant uncertainties. However, it should be noted that uncertainties arising from a shifting of the 24-h period are partially reduced by constraining the analysis to a 7-day period as performed in this study. Further, interpolated KED observations used as references were compared with the current literature. In all river basins except Juba-Shabelle, the interpolated fields closely resembled the spatial patterns reported in previous studies, thereby providing sound support for our findings. The discrepancy for the Juba-Shabelle basin might be due to a combination of low gauge station density and complex topography, which might hamper the proper representation of spatial precipitation patterns. Unfortunately, given the observational dataset available for this work, it cannot be verified at this stage whether the shortcomings in the SRFEs are due to shortcomings in the observed data or not. This question remains open for future research.

The ability of the SRFE products to accurately replicate observed precipitation data will largely determine the performance of any potential hydrological application (Bitew and Gebremichael 2011; Hossain et al. 2004). This work has shown that some SRFE products persistently performed better than others and that, for some products, the performances varied considerably depending on the morphoclimatic zone. For large-scale hydrological applications covering different morphoclimatic zones, the target is to achieve a stable performance over the whole area, rather than peak performances concentrated in particular zones. Three potential strategies to improve the performance of SRFE focusing on large-scale applications whose implementation is beyond the scope of this article are, however, worth mentioning. The first corresponds to bias correction of the selected SRFE products to ensure a correct replication of the observed precipitation data for a given time period. The second strategy consists of employing an ensemble of SRFE products. Considering the individual limitations of each product, it is advisable to use more than one product to account for uncertainty in rainfall representation. The third strategy comprises the creation of a performance-based merged SRFE product combining the respective strengths of individual products (see, e.g., Hossain and Anagnostou 2006).

Results of this work indicate that both RFE 2.0 and TRMM 3B42 succeeded in replicating the intraseasonal variability, the spatial distribution, and the timing of rainfall events. At the same time, CMORPH showed particular strength in replicating rainfall data over 
mountainous areas under sparse ground data conditions. Therefore, considering the data limitations and the scale of the study areas, it might be advisable to use these three products either as an ensemble or as a performancebased merged product.

Finally, future research will focus on the use of SRFE products as input data for hydrometeorological applications, potentially implementing the previously discussed strategies.

Acknowledgments. We would like to express our sincere gratitude to the Zambia Meteorological Department, the national members of the GLOWA Volta project, the Ethiopian National Meteorological Department, and staff of the SWALIM project for providing meteorological ground measurements, which made this study possible. Special acknowledgment also goes to NASA, ECMWF, JAXA, The University of Arizona, and NOAA/CPC for providing easy access to the SRFEs and their assistance in particular cases. We would also like to thank Niall McCormick for proofreading this article, as well as Alessandra Bianchi and Peter Burek for their technical support. Finally, Vera Thiemig would like to thank Steven de Jong and Derek Karssenberg of the University of Utrecht (the Netherlands) for their advice and their kind offer to host her in Utrecht to provide scientific and technical support.

\section{APPENDIX}

\section{Glossary}

$\begin{array}{ll}\text { AMSR-E } & \begin{array}{l}\text { Advanced Microwave Sounding } \\ \text { Radiometer for Earth Observing } \\ \text { System (EOS) }\end{array} \\ \text { AMSU } & \text { Advanced Microwave Sounding Unit } \\ \text { ANN } & \text { Artificial neural network } \\ \text { CMORPH } & \text { CPC morphing technique } \\ \text { CPC } & \text { Climate Prediction Center } \\ \text { ECMWF } & \text { European Centre for Medium-Range } \\ & \text { Weather Forecasts } \\ \text { ERA-40 } & \text { 40-yr ECMWF Re-Analysis } \\ \text { ERA-Interim } & \text { ECMWF Interim reanalysis } \\ \text { GMS } & \text { Geostationary Meteorological Satellite } \\ \text { GOES } & \text { Geostationary Operational } \\ & \text { Environmental Satellite } \\ \text { GPCC } & \text { Global Precipitation Climatology } \\ & \text { Center } \\ \text { GPI } & \text { GOES precipitation index } \\ \text { GPROF 6.0 } & \text { Goddard profiling algorithm, version 6 } \\ \text { GSMaP-MVK } & \text { Global Satellite Mapping of } \\ & \text { Precipitation moving vector } \\ & \text { with Kalman filter }\end{array}$

$\begin{array}{ll}\text { GTS } & \text { Global Telecommunication System } \\ \text { IR } & \text { Infrared } \\ \text { ITCZ } & \text { Intertropical convergence zone } \\ \text { JAXA } & \text { Japan Aerospace Exploration Agency } \\ \text { KED } & \text { Kriging with external drift } \\ \text { MAE } & \text { Mean absolute error } \\ \text { ML } & \text { Maximum likelihood } \\ \text { MSL } & \text { Above mean sea level } \\ \text { NASA } & \text { National Aeronautics and Space } \\ & \text { Administration } \\ \text { NOAA } & \text { National Oceanic and Atmospheric } \\ & \text { Administration } \\ \text { NP } & \text { "No peak" } \\ \text { NS } & \text { Nash-Sutcliffe efficiency } \\ \text { pBIAS } & \text { Percent bias } \\ \text { PERSIANN } & \text { Precipitation Estimation from } \\ & \text { Remotely Sensed Information } \\ & \text { using Artificial Neural Networks } \\ \text { PMW } & \text { Passive microwave } \\ \text { RFE } & \text { Rainfall estimation algorithm } \\ \text { RMSE } & \text { Root-mean-square error } \\ \text { SRFE } & \text { Satellite-based rainfall estimation } \\ \text { SRTM } & \text { Shuttle Radar Topographic Mission } \\ \text { SSM/I } & \text { Special Sensor Microwave Imager } \\ \text { TMI } & \text { TRMM Microwave Imager } \\ \text { TRMM } & \text { Tropical Rainfall Measuring Mission } \\ \text { WMO } & \text { World Meteorological Organization }\end{array}$


Artan, G., H. Gadain, J. L. Smith, K. Asante, C. J. Bandaragoda, and J. P. Verdin, 2007: Adequacy of satellite derived rainfall data for stream flow modeling. Nat. Hazards, 43, 167-185.

Asadullah, A., N. McIntyre, and M. Kigobe, 2008: Evaluation of five satellite products for estimation of rainfall over Uganda. Hydrol. Sci. J., 53, 1137-1150.

Behrangi, A., B. Khakbaz, T. C. Jaw, A. AghaKouchak, K. Hsu, and S. Sorooshian, 2011: Hydrologic evaluation of satellite precipitation products over a mid-size basin. J. Hydrol., 397, 225-237.

Bitew, M. M., and M. Gebremichael, 2011: Assessment of highresolution satellite rainfall for streamflow simulation in medium watersheds of the East African highlands. Hydrol. Earth Syst. Sci. Discuss., 7, 8213-8232.

Brown, J. E. M., 2006: An analysis of the performance of hybrid infrared and microwave satellite precipitation algorithms over India and adjacent regions. Remote Sens. Environ., 101, 63-81.

Burrough, P. A., and R. A. McDonnell, 1998: Principles of Geographical Information Systems. Oxford University Press, 333 pp.

Cattani, E., F. Torricella, S. Laviola, and V. Levizzani, 2009: On the statistical relationship between cloud optical and microphysical characteristics and rainfall intensity for convective storms over the Mediterranean. Nat. Hazards Earth Syst. Sci., 9, 2135-2142.

Cohen Liechti, T., J. P. Matos, J. L. Boillat, and A. J. Schleiss, 2011: Comparison and evaluation of satellite derived precipitation products for hydrological modeling of the Zambezi River Basin. Hydrol. Earth Syst. Sci. Discuss., 8, 8173-8201.

Dee, D. P., and Coauthors, 2011: The ERA-Interim reanalysis: Configuration and performance of the data assimilation system. Quart. J. Roy. Meteor. Soc., 137, 553-597.

Dinku, T., P. Ceccato, E. Grover-Kopec, M. Lemma, S. J. Connor, and C. F. Ropelewski, 2007: Validation of satellite rainfall products over East Africa's complex topography. Int. J. Remote Sens., 28, 1503-1526.

$\longrightarrow,-$ K K. Cressman, and S. J. Connor, 2010a: Evaluating detection skills of satellite rainfall estimates over desert locust recession regions. J. Appl. Meteor. Climatol., 49, 1322-1332.

— , F. Ruiz, S. J. Connor, and P. Ceccato, 2010b: Validation and intercomparison of satellite rainfall estimates over Colombia. J. Appl. Meteor. Climatol., 49, 1004-1014.

Diro, G. T., D. I. F. Grimes, E. Black, A. O'Neill, and E. PardoIguzquiza, 2009: Evaluation of reanalysis rainfall estimates over Ethiopia. Int. J. Climatol., 29, 67-78.

Ebert, E. E., M. J. Manton, P. A. Arkin, R. J. Allam, G. E. Holpin, and A. Gruber, 1996: Results from the GPCP Algorithm Intercomparison Programme. Bull. Amer. Meteor. Soc., 77, $2875-2887$.

_ J. E. Janowiak, and C. Kidd, 2007: Comparison of near-realtime precipitation estimates from satellite observations and numerical models. Bull. Amer. Meteor. Soc., 88, 47-64.

Goovaerts, P., 1997: Geostatistics for Natural Resources Evaluation. Oxford University Press, $483 \mathrm{pp}$.

— 2000: Geostatistical approaches for incorporating elevation into the spatial interpolation of rainfall. J. Hydrol., 228, 113129.

Grimes, D. I. F., and M. Diop, 2003: Satellite-based rainfall estimation for river flow forecasting in Africa. I: Rainfall estimates and hydrological forecasts. Hydrol. Sci. J., 48, 567-584.

Herman, A., V. B. Kumar, P. A. Arkin, and J. V. Kousky, 1997: Objectively determined 10-day African rainfall estimates created for famine early warning systems. Int. J. Remote Sens., 18, 2147-2159.
Hong, Y., K. L. Hsu, S. Sorooshian, and X. Gao, 2004: Precipitation estimation from remotely sensed imagery using an artificial neural network cloud classification system. J. Appl. Meteor., 43, 1834-1852.

,,-- H. Moradkhani, and S. Sorooshian, 2006: Uncertainty quantification of satellite precipitation estimation and Monte Carlo assessment of the error propagation into hydrologic response. Water Resour. Res., 42, W08421, doi:10.1029/ 2005WR004398.

Hossain, F., and E. N. Anagnostou, 2006: Assessment of a multidimensional satellite rainfall error model for ensemble generation of satellite rainfall data. IEEE Geosci. Remote Sens. Lett., 3, 419-423.

— _ _ and T. Dinku, 2004: Sensitivity analyses of satellite rainfall retrieval and sampling error on flood prediction uncertainty. IEEE Trans. Geosci. Remote Sens., 42, 130139.

Hsu, K. L., X. Gao, S. Sorooshian, and H. V. Gupta, 1997: Precipitation estimation from remotely sensed information using artificial neural networks. J. Appl. Meteor., 36, 11761190 .

Huffman, G. J., and Coauthors, 2007: The TRMM Multisatellite Precipitation Analysis (TMPA): Quasi-global, multiyear, combined-sensor precipitation estimates at fine scales. J. Hydrometeor., 8, 38-55.

— R. F. Adler, D. T. Bolvin, and E. Nelkin, 2010: The TRMM Multi-Satellite Precipitation Analysis. Satellite Rainfall Applications for Surface Hydrology, F. Hossian and M. Gebremichael, Eds., Springer, 3-22.

Hughes, D. A., 2006: Comparison of satellite rainfall data with observations from gauging station networks. J. Hydrol., 327, 399-410.

Isaaks, E. H., and R. M. Srivastava, 1989: An Introduction to Applied Geostatistics. Oxford University Press, $561 \mathrm{pp}$.

Jobard, I., F. Chopin, J. C. Berges, and R. Roca, 2011: An intercomparison of 10-day satellite precipitation products during West African monsoon. Int. J. Remote Sens., 32, 2353-2376.

Journel, A. G., and C. J. Huijbregts, 1978: Mining Geostatistics. Academic Press, 600 pp.

Joyce, R. J., J. E. Janowiak, P. A. Arkin, and P. Xie, 2004: CMORPH: A method that produces global precipitation estimates from passive microwave and infrared data at high spatial and temporal resolution. J. Hydrometeor., 5, 487503.

Kidd, C., V. Levizzani, J. Turk, and R. Ferraro, 2009: Satellite precipitation measurements for water resource monitoring. J. Amer. Water Resour. Assoc., 45, 567-579.

Kummerow, C., and Coauthors, 2001: The evolution of the Goddard profiling algorithm (GPROF) for rainfall estimation from passive microwave sensors. J. Appl. Meteor., 40, 1801-1820.

Laurent, H., I. Jobard, and A. Toma, 1998: Validation of satellite and ground-based estimates of precipitation over the Sahel. Atmos. Res., 47-48, 651-670.

Ly, S., C. Charles, and A. Degré, 2011: Geostatistical interpolation of daily rainfall at catchment scale: The use of several variogram models in the Ourthe and Ambleve catchments, Belgium. Hydrol. Earth Syst. Sci., 15, 2259-2274.

Maidment, R., E. Tarnavsky, D. Grimes, and R. Allan, 2010: TARCAT-TAMSAT African rainfall climatology and time series. Fifth IPWG Workshop on Precipitation Measurements, IPWG, Hamburg, Germany. [Available online at http://www. isac.cnr.it/ ipwg/meetings/hamburg-2010/posters/Maidment. pdf.] 
McCollum, J. R., A. Gruber, and M. B. Ba, 2000: Discrepancy between gauges and satellite estimates of rainfall in equatorial Africa. J. Appl. Meteor., 39, 666-679.

Nash, J. E. and J. V. Sutcliffe, 1970: River flow forecasting through conceptual models. Part I: A discussion of principles. J. Hydrol, 10, 282-290.

Nesbitt, S. W., D. J. Gochis, and T. J. Lang, 2008: The diurnal cycle of clouds and precipitation along the Sierra Madre Occidental observed during NAME-2004: Implications for warm season precipitation estimation in complex terrain. J. Hydrometeor., 9, 728-743.

Nicholson, S. E., and Coauthors, 2003: Validation of TRMM and other rainfall estimates with a high-density gauge dataset for West Africa. Part I: Validation of GPCC rainfall product and pre-TRMM satellite and blended products. J. Appl. Meteor., 42, 1337-1354.

Olson, W. S., S. Yang, J. E. Stout, and M. Grecu, 2007: The Goddard Profiling Algorithm (GPROF): Description and current applications. Measuring Precipitation from Space, V. Levizzani, P. Bauer, and F. J. Turk, Eds., Springer-Verlag, 179-188.

Pebesma, E. J., and C. G. Wesseling, 1998: Gstat: A program for geostatistical modelling, prediction and simulation. Comput. Geosci., 24, 17-31.

Romilly, T. G., and M. Gebremichael, 2011: Evaluation of satellite rainfall estimates over Ethiopian river basins. Hydrol. Earth Syst. Sci., 15, 1505-1514.

Shahin, D. M., 2002: Hydrology and Water Resources of Africa. Water Science and Technology Library, Vol. 41, Kluwer Academic Publishers, 686 pp.

Smith, E. A., and Coauthors, 1998: Results of WetNet PIP-2 project. J. Atmos. Sci., 55, 1483-1536.

Smith, T. M., P. A. Arkin, J. J. Bates, and G. J. Huffman, 2006: Estimating bias of satellite-based precipitation estimates. J. Hydrometeor., 7, 841-856.

Sorooshian, S., K. L. Hsu, X. Gao, H. V. Gupta, B. Imam, and D. Braithwaite, 2000: Evaluation of PERSIANN system satellite-based estimates of tropical rainfall. Bull. Amer. Meteor. Soc., 81, 2035-2046.

Stisen, S., and I. Sandholt, 2010: Evaluation of remote-sensingbased rainfall products through predictive capability in hydrological runoff modelling. Hydrol. Processes, 24, 879-891.
Symeonakis, E., R. Bonifaçio, and N. Drake, 2009: A comparison of rainfall estimation techniques for sub-Saharan Africa. Int. J. Appl. Earth Obs. Geoinf., 11, 15-26.

The NOAA Climate Prediction Center, cited 2002: African rainfall estimation algorithm version 2.0. [Available online from http://www.cpc.ncep.noaa.gov/products/fews/RFE2.0_tech. pdf.]

Thorne, V., P. Coakeley, D. Grimes, and G. Dugdale, 2001: Comparison of TAMSAT and CPC rainfall estimates with raingauges, for southern Africa. Int. J. Remote Sens., 22, 19511974.

Tian, Y., C. D. Peters-Lidard, and J. B. Eylander, 2010: Real-time bias reduction for satellite-based precipitation estimates. J. Hydrometeor., 11, 1275-1285.

Ushio, T., and M. Kachi, 2010: Kalman filtering applications for Global Satellite Mapping of Precipitation (GSMaP). Satellite Rainfall Applications for Surface Hydrology, F. Hossian and M. Gebremichael, Eds., Springer Publishing Company, 105123.

- and Coauthors, 2009: A Kalman filter approach to the global satellite mapping of precipitation (GSMaP) from combined passive microwave and infrared radiometric data. J. Meteor. Soc. Japan, 87A, 137-151.

Xie, P., and P. A. Arkin, 1995: An intercomparison of gauge observations and satellite estimates of monthly precipitation. J. Appl. Meteor., 34, 1143-1160.

$\longrightarrow$, and — 1996: Analyses of global monthly precipitation using gauge observations, satellite estimates, and numerical model predictions. J. Climate, 9, 840-858.

_ S.-H. Yoo, R. Joyce, and Y. Yarosh, 2011: Bias-corrected CMORPH: A 13-year analysis of high-resolution global precipitation. Geophysical Research Abstracts, Vol. 13, Abstract EGU2011-1809. [Available online at http://meetingorganizer. copernicus.org/EGU2011/EGU2011-1809.pdf.]

Yapo, P. O., H. V. Gupta, and S. Sorooshian, 1996: Automatic calibration of conceptual rainfall-runoff models: Sensitivity to calibration data. J. Hydrol., 181, 23-48.

Yilmaz, K. K., T. S. Hogue, K. L. Hsu, S. Sorooshian, H. V. Gupta, and T. Wagener, 2005: Intercomparison of rain gauge, radar, and satellite-based precipitation estimates with emphasis on hydrologic forecasting. J. Hydrometeor., 6, 497-517. 